\title{
A Hedonic Price Index for Airline Travel ${ }^{*}$
}

\author{
David H. Good \\ Robin C. Sickles \\ Indiana University \\ Bloomington, Indiana \\ Rice University \\ Houston, Texas \\ Jesse C. Weiher \\ Federal Deposit Insurance Corporation \\ Washington, D. C.
}

October 18, 2005

\begin{abstract}
Our research takes an exhaustive approach to measurement issues in price index construction for the BLS airfare index. We pursue a number of the objectives for dealing with the biases that the 1997 CPI Commission recommended and detail a protocol for data collection and analysis that can be replicated and can be enhanced by availability of additional data sources. We find an upward bias in the BLS airfare index over the period considered. However, because of issues of practicality and implementability of the methods we utilize in our analysis, the goals of the Commission recommendations remain illusive and problematic in being more broadly applied to other components of the CPI.
\end{abstract}

JEL Classification Numbers: D46, C23, C43, L93

Keywords: Consumer price index, airline industry, hedonic regression, panel data

\footnotetext{
${ }^{*}$ This research was funded by a grant from the Bureau of Labor Statistics. Preliminary drafts were prepared for the BLS conference "Issues in Measuring Price Changes and Consumption", June 2000 and the Brookings Institution's "Workshop on Transportation Output and Productivity. We would like to thank without implicating Dennis Fixler, John Greenlees, Robert Gordon, Clint Oster, Jack Triplett and Cliff Winston for providing suggestions and criticisms that substantially improved the paper. The usual caveat applies.
} 


\section{Introduction}

Ideally, the Consumer Price Index measures the price of a fixed market basket over time. The CPI has a wide variety of uses as both a measure of the overall inflation in the economy and as a cost of living index (COLI). The CPI Commission outlined several features of the CPI which tend to make it less useful as a COLI. The issues raised by the CPI Commission are discussed at length in Boskin et al. (1997, 1998) and Boskin and Jorgenson (1997). First, because the market basket is fixed, the CPI does not allow for consumers to respond to price changes by substituting away from commodities with higher price increases towards commodities with lower price increases (substitution bias). Second, because price changes are considered only within outlets, the index does not allow for consumers to substitute away from higher priced outlets towards lower priced outlets for identical items (outlet substitution bias). Third, since the market basket is typically sparse in details about quality, the CPI does not always consider the possibility that price increases may be caused by unmeasured quality improvements in the items that constitute the fixed market basket that increase consumer welfare (quality change bias).

The CPI Commission concluded that changes in the CPI overestimated the change in the Cost of Living by about 1.1 percent per year. They estimated the portions of bias that could be attributed to substitution bias and outlet substitution at 0.4 and 0.1 percent per year. They also estimated the portion that could be attributed to failing to control for the quality of existing commodities and to incorporate new commodities at 0.6 percent per year. The commission concluded that impacts of this bias were far reaching since many government expenditure increases, most notably Social Security, are tied into the CPI. Consequently, the bias has led the federal government to overcompensate individuals for the cost of living leading some to conclude this overcompensation has accelerated inflation as more dollars in benefits chase a fixed level of goods. The commission generated a number of recommendations. Among them were: (i) use hedonic statistical methods to adjust for quality change; (ii) reweight the consumption basket more frequently; (iii) increase the pace of sampling so that new goods can be accounted for more rapidly; (iv) study the individual components of the CPI to determine which components provide the most information about future movements in the index and which components have movements which are mostly irrelevant to movements in the total; (v) move toward the notion of a new "basket" every year; and (vi) use new sources of data such as scanner data.

This paper describes the implications of implementing some of these recommendations in the context of one specific component of the CPI, domestic airline fares. To our knowledge, ours is the first paper to integrate so many of these recommendations simultaneously: re-weighting every period, hedonic models and the use of scanner-like data. We view the consumer's market basket of airline travel commodities as com- 
posed of a number of alternative city-pair routes. The airline fares portion of the CPI is amenable to the CPI Commission's recommendations because data sets of ticket sales already exist. In other industries, improved data collection may prove difficult because national level data collection requires cooperation that these firms are unlikely to willingly provide.

Based on the U.S. Department of Transportation's (USDOT) origin and destination data $(O \& D)$ we estimate a quality-adjusted price index for airline fares using a hedonic price regression which includes quality characteristics as well as time dummies. From these estimates we are able to construct quality adjusted changes in price over time. Basing our adjustments on the O\&D database is also useful in dealing with market basket composition issues. Because the weights consists of sales data, they can be adjusted as the quantities sold adjust. When a new product is introduced (e.g. an airline adding a new route, the introduction of a business class fare, etc.) it shows up automatically in the data. Interregional comparisons can be made because the data collection techniques are the same across regions. Still there are some limitations: airline data are collected quarterly rather than monthly (making construction of a monthly airfare index difficult), smaller airlines tend to underreport and some information about fare class is censored. Even so, the aviation O\&D data have a much broader geographical coverage and longer time series than any other single source publicly available sales data series in any other industry of which we aware.

The paper is organized as follows. In the next section we discuss developments in the literature on price indices and on specific problems with the construction of an air travel price index. In section 3, we discuss the methods employed by the BLS to calculate the consumer price index for airfares. In section 4 , we present the construction of measurements for a number of fare characteristics and present their trends during the period of our study, 1979I-1992IV. In section 5, we construct a new method that explicitly recognizes the role of quality characteristics on the consumer's valuation of airline service. This reduced form approach utilizes hedonic price index methods to weight down the actual reported output and thus weight up the effective price of airline service. Our last section presents results and provides concluding remarks.

\section{Sources of Bias in the CPI: Suggested Corrections and their Impli- cations for the Airline Price Index}

\subsection{The CPI Commission and the Nature of CPI Bias}

As we pointed out in the introduction, the CPI Commission concluded that changes in the Consumer Price Index overestimated the change in the Cost of Living by about 1.1 percent. The bias was attributed to three factors: the substitution bias - measured at 0.4 percent, outlet substitution bias - measured at 0.1 percent, and quality change 
bias (or new goods bias) - measured at 0.6 percent. Boskin et al. (1998) discuss the commission findings and describe the sources of these biases in detail. They also discuss another type of bias that few have deemed important. This is a "when" bias (referred to in this paper as "intertemporal substitution bias"). Price data tend to be collected during the week, whereas an increasing share of purchases are made on weekends and holidays. Many outlets even emphasize weekend sales. Thus there may be a 'when' bias as well as a 'what' and a 'where' bias."

The Commission's conclusions generated a large quantity of further research - both supporting and refuting the Commission's findings. Abraham, Greenlees and Moulton (1998) provide the BLS response to the CPI Commission's report and describe initiatives at the BLS that are intended to improve the accuracy of the CPI (some of which were enacted before the Commission's report). To address lower level substitution bias, the BLS moved towards using a geometric mean instead of an arithmetic mean and to address upper level substitution bias, the BLS began issuing alternative superlative indexes for comparison. When dealing with quality bias, they point out that the BLS already uses a linking procedure to adjust for changes in quality due to new goods. Additionally, they dispute the notion that failing to adjust for quality would necessarily result in an overstatement of the rate of growth of prices. For instance, they point out that reduced convenience and comfort of air travel might lead to an underestimate of inflation. However, they agree that greater use of hedonic statistical techniques could help the BLS account explicitly for changes in quality and assert that the BLS is moving towards increased adoption of hedonic techniques. They also dispute the Commission's reliance on previous studies with which the authors do not agree. Deaton (1998), among others, pointed out just how vexing adjustments for quality changes can be and discussed a number of examples that illustrate that there are often welfare consequences of quality change that are unobservable. Recent improvements and changes, adopted as a result of the CPI Commission's findings, have been put in place by the statistical agencies and the BLS in particular. The statistical agencies have begun to work with scanner data and are considering implementing hedonic regression techniques (Diewert, 1998).

Changing the CPI so that it can more accurately reflect a cost-of-living index cannot be accomplished, however, without addressing very fundamental questions which appear to still be open questions (Pollak, 1998). Whose cost-of-living do we want to model? How can we deal with an economy in which the law of one price does not hold and consumers must search for the best price? What exactly is a good? Pollak's remedies include separating technical issues from political ones as much as possible and convening a committee of experts to study these technical issues and report on them. The political issues could be addressed, not by modifying the CPI, but by changing the procedure with which tax brackets and transfer payments are indexed (say by lowering the index from the CPI projections by 1 percentage point). 
Criticism of the CPI Commission's report is summarized by Baker (1998). He notes that there are at least six distinct problems that can be identified in the commission's estimates of quality and new goods bias. They are:

"...1. Many of the estimates depend exclusively on introspection - thought experiments in which the commission members speculate on the amount of bias in the index. The commissioners use introspection to make estimates of bias that cover $58.33 \%$ of the index and account for 0.171 of the 0.612 -percentage-point estimate of quality and new goods bias.

2. In a set of estimates, the commission has misinterpreted the findings of earlier research. This problem arises in estimates of bias in items that make up $10.37 \%$ of the index and account for 0.242 percentage points of the commission's estimate of bias.

3. In some estimates, The commission has made dubious extrapolations from research. Estimates that cover $6.47 \%$ of the index and account for 0.038 percentage points of bias fall into this category.

4. In another set of estimates, BLS has implemented a procedural change that has not been taken into account. These estimates cover $5.73 \%$ of the index and account for 0.172 percentage points of bias.

5. In the commission's treatment of personal financial services, a category that covers $0.4 \%$ of the index and accounts for 0.009 percentage points of bias, the source of bias identified (if accurate) should apply to the measure of personal income in the national income and product accounts, not to the consumer price index.

6. One of the commission's estimates (for nonprescription drugs and medical supplies) has no support whatsoever. This estimate covers $0.39 \%$ of the CPI and accounts for 0.004 percentage points of bias...."

In the next sections we undertake the in-depth analysis suggested by the commission and summarized by Nordhaus (1998) to construct a consumer price index for air travel. Nordhaus pointed to the need to utilize an appropriately stratified sample of commodities, and to more completely and accurately estimate the price of services actually delivered. In so doing he noted that one could produce better estimates of unmeasured quality changes as well as estimates of reliability. We use these dictums in our analysis below.

\subsection{CPI Bias and Quality Issues in the U.S. Airline Industry}

In this section we discuss how CPI bias might appear in the index for airline fares as well as discuss research into quality issues in the U.S. Airline Industry.

Most quality adjustments made by the CPI use an imputation procedure that estimates the price change of a new product (or old product with new quality feature) by the average price changes of similar products currently in the market. This assumes that the underlying price change of the service not currently available would have been the 
same as the price changes of services currently in the market. However, if this is not the case, then the imputation procedure would miss important price changes. Armknecht and Ginsburg (1992) illustrate this problem in the context of airline fares:

"...As an example of this situation consider airfares. The airlines at one point in time introduced a new set of discount airfares to replace supersaver fares. Originally, supersaver fares required a 30-day prepayment to obtain the reduced fare. The new discount fares introduced a lower price structure than the supersavers and required the 30-day prepayment. However, along with the lower fares came a 50-percent cancellation penalty, a quality difference between the fares that may/should make them noncomparable. If no other airline price changes occurred during this month, the exclusion of the discount quotes would result in an imputed price change of zero because all other airline fares (coach and first-class) remained the same. The index, therefore, misses any possible price change occurring with the introduction of the lower discount fares under current procedures (this problem would exist even if other fares changed but at a different rate)."

Gordon and Griliches (1997) construct estimates of quality-change and new-product bias for major and selected minor components of the CPI-U (urban workers) and found substantial biases in selected time intervals. For example, in public transportation they estimate that the CPI-U was biased by $2.66 \%$ /year from 1972-77 and 4.60\%/year from 1977-1982, with no bias in the period 1982-1996. The Laspeyres' index that the CPI uses is well known as an upper bound on a true COL index. Gordon and Griliches use a formulation that is more similar to a Paasche index. It is a long-standing theoretical result that the Paasche index is a lower bound on the true COL index. A distinguishing feature of the work we pursue below is that we use a hedonic regression that holds without considering weighting issues and thus we have no reason to believe that our price index is biased in any direction.

Gordon and Griliches point out that some quality improvements are quite problematic when attempting to incorporate them into a price index because they represent an abatement of "bads" that also were not considered in the index. For example, increases in the price of a flight due to increased safety measures may be a price change due to quality improvement. However, unless we also deal with the cost that was imposed due to increased risk of plane malfunction or terrorism, we will not be accurately reflecting the COL associated with it. It may be easily argued that patrons were better off before terrorism was ever a threat than after security measures were put in place. By not specifically accounting for the costs to increased risks, we will be overestimating the effect of security on welfare and underestimating the cost of living. The security issue is not explicitly accounted for in our analysis, but this is an interesting point. One possible modeling approach to use in this regard that we have not pursued is the directional distance function paradigm introduced by Färe, Grosskopf, Norris, and Zhang (1994) and recently utilized in the context of the impact of environmental "bads" on growth 
accounting by Jeon and Sickles (2004).

Related to the CPI Commission's substitution bias and outlet substitution bias is another type of substitution bias that few have discussed (although the Commission did recognize that this bias exists). This bias results from short term, intertemporal substitution. The CPI samples only prices and uses the Consumer Expenditure Survey to attach sales weights to the prices that are sampled. This implies that price variations do not change quantities purchased. There is a chance that a particular outlet accidentally sets a price that is very high and elicits few sales. The outlet might notice the mistake quickly and lower price accordingly. However, if the CPI samples the high price, the CPI measures a price increase due to a temporary mistake that affected few people, if anyone at all.

For illustration, consider this example: An airline sets a high price on a first class, unrestricted ticket from Houston-Hobby (HOU) to Baltimore Washington (BWI) because of an error in estimating demand. The price is so high that no purchases are made. Two days later, the airline lowers its price and registers sales. The CPI, using the SABRE reservation system, samples the high price. Perhaps it also samples the lower price. However, the average price during that month is much higher than it would have been had the CPI ignored the higher price which had no sales. As a result, there is an upward bias in price change from the previous month to the current month due to measuring an advertised price that elicited no purchases. If the airline did not make the same pricing mistake in the next month, the price level that month would be correct. However, the price change from the first month to the second month would be negative when it should have been zero (a downward bias).

This would be an example of "substitution" bias if people responded to the higher price by purchasing a ticket from the same airline for the same route but with a different fare class. It would be outlet substitution bias if people responded by purchasing a ticket sold by another airline. However, if some people responded simply by waiting for two or more days and purchasing the same ticket at the lower price, then there would be no "bias" as recognized by the CPI Commission previously talked about would apply. This type of intertemporal substitution would also occur if people responded to upcoming sales by holding off on purchases until the sale took place. Since many sales are advertised before hand, one might conclude that prices preceding sales events would correspond to fewer purchases. By treating each price sampled for the same service in the same period as equal, these substitutions are missed. This would not be a problem if BLS sampled prices and sales rather than just prices.

Although they did not construct a price index, Morrison and Winston (1995) calculated marginal valuations of quality characteristics via an airline choice model. The marginal value of an additional mile for travelers who accumulated 3,501 to 15,000 miles was estimated to be 13 cents while for travelers who accumulated 15,001 to 80,000 miles it was 21.5 cents. They estimated the cost of restrictions on a discount flight via a 
binary, probit model of choice between unrestricted vs. restricted fairs. Although there appeared to be no significant costs for the leisure travel the business traveler incurred some significant costs. Saturday night restrictions added $\$ 219$ dollars of disutility. Advanced reservation requirements imposed a cost of $\$ 3.68$ a day. Overall, business travelers (via a compensated variation method) were willing to pay $\$ 87$ dollars per trip to avoid restrictions, a substantial portion of which was due to the Saturday night stay $(\$ 67)$. They also estimate a fare equation for each carrier to investigate whether multimarket contact has an affect on prices. Airlines that competed with each other in many markets may have stronger incentives to engage in tacit collusion (and avoid fare wars) than airlines that compete only in a few markets. Morrison and Winston found that multimarket contact did have an effect on fares in the industry but that the effects were highly cyclical. When the economy is growing rapidly fares were higher where there was multimarket contact than where there was none. However, there are recessionary periods where the opposite effect occurs. Multimarket contact might be considered a benefit to consumers because it allows for the possibility of greater competition (see e.g., Perloff, Sickles, and Weiher, 2003). Even in the presence of collusion on prices, airlines might still compete along quality dimensions. An example is Continental competing with United in the Dallas-Fort Worth/Washington, D.C. market, in which there is anecdotal evidence of price collusion, by allowing for more carry-on luggage space. United tried to implement a carry-on size limit and the matter is still in the courts. ${ }^{1}$

A number of studies have found that the consumer has benefited from airline deregulation. Caves, Christensen, Tretheway, and Windle (1987) showed that deregulation increased the passenger-mile productivity growth rate between 1.3 and 1.6 percent per year. Morrison and Winston (1995) highlighted a number of important benefits accruing to consumers: 1) fares were about 22 percent lower with deregulation; 2) a benefit of about $\$ 10.3$ billion per year resulted from the elimination of route restrictions and an increased use of hub-and-spoke networks; 3) the proportion of passengers with direct nonstop flights increased, even though passengers often had to take an indirect route associated with the hub-and-spoke network structure; and 4) passengers who had to change planes rarely had to change airlines due to increases in network size.

It should be noted, however, that the benefits of such innovations as the hub-andspoke systems may be overstated due to longer travel time due to longer flight segments,

\footnotetext{
${ }^{1}$ Continental Airlines, Inc. v. United Airlines, Inc., 126 F. Supp.2d 962 (E.D. Va. 2001) - Continental Airlines challenged a rule at Dulles Airport imposing limits on the size of carry-on baggage. The Association of Air Carriers serving Dulles had imposed the rule at the insistence of United Airlines. The court struck down the rule, finding that it was not justified by safety and efficiency concerns, and that United attempted to influence the standard-setting process in an anticompetitive manner in order to relieve it from competitive pressure from air carriers which permitted larger carry-ons. However, that decision has been vacated, citing "unique structure of Dulles," and remanded for further proceedings. See Continental Airlines, Inc. v. United Airlines, Inc., 277 F.3d 499 (4th Cir. 2002).
} 
longer waiting times for the flights themselves because of scheduling and because of congestion. Ground time has increased by five minutes regardless of distance traveled. It would seem, however, that the cost of increase travel time ( $\$ 2.8$ billion per year in 1995) was more than offset by the benefit of hub-and-spoke systems (Morrison and Winston, 1995).

\subsection{How CPI Bias is Being Addressed}

As mentioned earlier, the BLS has implemented changes in the construction of the CPI in order to improve the accuracy of the index. Some of the improvements came as a result of the CPI Commission's report and some were already being contemplated. To address lower level substitution bias the BLS moved towards using a geometric mean instead of an arithmetic mean. To address upper level substitution bias the BLS began issuing alternative superlative indexes for comparison. Other changes also were made to ameliorate outlet substitution bias. To address quality change bias the BLS commissioned several studies to investigate how hedonic price functions might be used to control for changes in quality of items in the market basket. We discuss below how such hedonic approaches have been applied to other industries and why the airline travel index in particular could benefit from controlling for quality characteristics hedonically.

The automobile industry was one of the first industries to utilize hedonic methods (Griliches, 1961). The analysis of marginal prices of housing attributes through computation of hedonic indices began in the late 1960's (e.g. Ridker and Henning, 1967, 1992) and 1970's ( Rosen, 1974). Hedonic indices were applied to computers in the mid 1980's (e.g. Triplett, 1984) and more recently information technology products in general (Triplett, 2004). Other markets whose prices were revalued using hedonic techniques include the medical field (Primont and Kokoski, 1990; Trajtenberg, 1990) and university education (Schwartz and Scafidi, 2000). To our knowledge, our development a price index for airline fares via an hedonic price approach is new to the literature. For a clear and concise review of hedonic regression theory we suggest the reader review

Quigley (1982). Armknecht and Ginsburg (1992) offer hedonic regressions as a way to address the issue of quality that arises when new products enter the market. Hedonic models not only help in estimating quality differences resulting from a change in characteristics. They also enhance the analyst's information about the quality composition of services offered. Specifically, the models can identify those quality characteristics that provide the largest impacts on price.

Armknecht and Ginsburg suggest two important benefits related to these insights. First, analysts can create a formal statistical test for whether changes in a quality characteristic render the old and new services incomparable. Second, the factors that provide the most impact on price can be used to redesign collection documents used by the CPI. By ordering the quality characteristics according to importance, e.g., field 
staff can pick the most appropriate substitute by the most important characteristics according to the appropriate order. Pakes (2003) furthers this line of thinking by directly comparing matched model indexes to hedonic indexes in the market for PCs.

Pakes (2005) cautions the researcher that imperfect competition prevents the hedonic coefficients from being accurately interpreted as the consumer's marginal willingnessto-pay. He makes this point with a hypothetical example involving medications that illustrates the problem of interpreting the derivatives of a hedonic price function as either willingness to pay derivatives or cost derivatives since empirical estimates are essentially reduced form solutions formed from a complex equilibrium process. Pakes makes it clear, however, that losing the interpretation of hedonic coefficients derivatives of a hedonic price function as either willingness to pay derivatives or cost derivatives does not invalidate the use of hedonics to control for quality in a price index. Pakes' concern about the interpretation of hedonic coefficients involves situations where the commodity is defined too broadly. An example is one in which the consumers buying drug A are not the same consumers buying drug B. If one were to run a separate regression for each drug, and if the toxicity of drug B were to reduce over time, we would expect to see a negative parameter estimate for toxicity.

Using this line of reasoning the large number of customers shopping among the various characteristics of an airline ticket would validate the interpretability of hedonic coefficients. Parameter estimates in our analysis below thus retain their interpretation as measures of the marginal willingness to pay because airline travel is not so broad a service as to apply to completely different consumer groups. Airlines do have different marketing strategies for different groups of consumers (business versus leisure travelers, for example). However, these groups of consumers are not exclusive sets of consumers. An airline passenger who is travelling on business now will be traveling for leisure later. Someone who buys a first class ticket today may well buy a discount coach ticket tomorrow. It seems reasonable to assume, e.g., that a first class ticket was bought when the premium for first class was sufficiently small and that a coach ticket was bought when the premium was too large. In Pakes' drug example, it is hard to conceive of a consumer buying the more toxic drug if the price were lower. However, we cannot think of any quality attribute associated with an airline ticket that consumers could not be induced to change through a sufficient change in price.

\section{Simulating the Current BLS Approach for Constructing an Airfares CPI}

The airline fares index is the largest component (61\%) of the public transportation index. It accounts for $.814 \%$ of the total CPI. The BLS selects approximately 850 observations for its airline fares index. All regularly scheduled commercial airline trips departing from airports in the 87 cities in the CPI are eligible for use in the index. When 
the city does not have a qualifying airport, the qualifying airport from the nearest city is designated as the point of departure. Reflecting the average pattern of trips from the US DOT's origin/destination survey, $2 \%$ are first class, $4 \%$ are full coach fare, and $94 \%$ are discounted coach fares. The origin/destination survey does not identify types of discount fares. Thus the BLS assumes that half of the discounted coach fares the lowest available fare regardless of restrictions. The BLS assumes that the other half includes specific restrictions. The fare at the time of sampling is found in the SABRE reservation system. This is the same system that historically has been used by much of the travel industry, though its use has declined substantially over the last two decades. When an airline discontinues a discount fare that is being priced, the BLS substitutes the closest available alternative. However, applicable restrictions may change, thus changing the "quality" of the flight. BLS estimates the value of this change. If the value is high, the two fares will not be compared. Usually, however, the change is not large and the fares are compared and reflected in the CPI.

Below we more formally describe the process used by the BLS during our study period (1979 through 1992) and the new procedure that they used beginning in 1999. Since we are interested in evaluating the current procedure of BLS but must evaluate it using older data we construct price indices using both methods. The first method is used for comparison to historical indices. The second is used to identify the historical index had current procedures been used. Below we describe the historical procedure and then how it changed in 1999.

Step 1 (Primary Sampling): Conduct random price sampling for all items in the market basket. The market basket is a set of origin-destination-fare class triples in each Price Sampling Unit (PSU). The PSU is a county within one of the metropolitan areas which is covered by the consumer price index for all urban consumers (CPI-U).

Step 2 (Aggregation process pre 1999): Compute the Air Fare CPI

$$
\frac{A F C P I_{t}}{A F C P I_{t-1}}=\sum_{j} s_{j}\left(\sum_{i} w_{i j} \frac{p_{i j t}}{p_{i j t-1}}\right)
$$

where the subscript $i$ represents the item in the basket, $j$ represents the PSU and $t$ represents the time period. Weights $w_{i j}$ are obtained from the Consumer Expenditure Survey and weights $s_{j}$ represent the fraction of sales which occur in PSUj compared to the entire US.

Step 2' (Aggregation process post 1999): Compute the Air Fare CPI

$$
\frac{A F C P I_{t}}{A F C P I_{t-1}}=\sum_{j} s_{j}\left(\prod_{i} w_{i j} \frac{p_{i j t}}{p_{i j t-1}}\right)
$$


The difference between step 2 and step 2' is the use of arithmetic means prior to 1999 and geometric means after 1999 at the stage where price ratios are aggregated to the level of the PSU.

Implementation of these procedures is complicated by inadequate information on the appropriate market basket and the proper weights. Unfortunately, the only market basket and weights available from BLS are those currently used and they were constructed in 1998. Market baskets and weights for earlier years are unavailable because the BLS apparently did not archive this data. Information on deeply discounted fares with corresponding restrictions thus were not available in many of the years that our study covers. ${ }^{2}$

\section{Data Sources Used to Compute a New Quality Adjusted Airfare Price Index}

The CPI is best computed when the products under consideration are simple homogeneous commodities. This does not describe the air transport industry, particularly over our study period, because air travel takes place between many different origins and destinations over alternative paths and with differing levels of service. In this section we discuss several of the important dimensions of air travel and how they affect the price of travel through changes in quality. These issues fall into seven broad quality categories: Network configuration, flight convenience, passenger amenity, airport and flight delay, ticket restrictions, yield management, and frequent flier programs (zero coupon tickets). These categories will at times overlap. In many cases our choice of study period, from 1979 through 1992 is both interesting and restrictive. It is interesting because many fare innovations and service quality changes occurred during this time period following the deregulation of the industry in 1978. It is restrictive because many of the data sets which would be useful to identify service quality changes do not span our study period.

\subsection{Network Configuration}

Prior to deregulation, airline networks were constructed on a piecemeal manner. Airlines were granted routes out of "public convenience and necessity." This often led to rather

\footnotetext{
${ }^{2}$ One possible way to deal with the lack of weights would be to use the market basket from 1998 while acknowledging that the basket and weights changed over time. An alternative approach would be to use fare mixes each quarter from the Origin and Destination Survey. The first approach uses an incorrect market basket but keeps a constant fare-class mix. The second approach uses fare-class mixes that are closer to what would have been in older market baskets but loses some of the fixed-basket qualities of the CPI. We settled on eliminating fare class information all together in constructing weights. This produced a series that was quite similar to the CPI index and appeared to be a better approximation to the use of an obviously incorrect fare mix.
} 
inconvenient routing for passengers, particularly to small communities. Deregulation opened access to all routes and by 1982 airlines could serve whatever routes they wished. Airlines responded by developing hub-and-spoke networks, adding some destinations and dropping others. In our study we consider three hedonic characteristics of the airlines' network configuration: the indirectness of routing, change of planes, and the number of airlines used to complete the trip.

Airlines find different network configurations useful because they allow for higher passenger densities on individual routes, potentially allowing the airlines to take advantage of economies of equipment size (larger aircraft tend to have lower costs per passenger mile) and higher load factors (filling otherwise empty seats on an aircraft costs the airline very little). In a simple network involving 5 cities (one serving as the hub), the cities can be connected with at most one change of plane service with as few as 4 round trip flights. Connecting the cities together with a network providing nonstop service would require 10 round trip flights. Adding an additional city would require one more round trip flight with a hub-and-spoke or five more round trip flights with direct only.

Because passenger time is valuable indirect routing is a cost to the passenger. The cost increases when the indirect routing involves changes of planes through a congested hub. On the other hand, indirectly routed passengers often will accrue more frequent flyer miles than a directly routed passenger.

When an airline does not serve both the origin and destination or serves them only indirectly, passengers must take part of their trip on one airline and the remainder on at least one other airline (interlining). Passengers perceive a lower quality of service when interlined. Baggage will more likely be mishandled or misdirected, the distance between gates at the connecting airport is usually greater, and there is the increased likelihood of a missed connection.

We measure the network characteristics at the individual ticket level. Using the DB1A, we identify the origin and the ultimate destination as indicated by a trip break. Approximately $30 \%$ of trips involve one way tickets (no trip breaks), $65 \%$ are one way (one trip break at the destination), and the remaining 5\% involve open jaw or multibreak tickets. In order to gain an understanding of the bulk of trips we limit our attention to either one way or round trip tickets and develop separate models for each. The changing pattern of these tickets is described in Figure 4.1 For each trip type, we identify the complexity of the trip from the DB1A at the ticket level. The travel itinerary allows us to measure the number of segments (changes of planes with the same carrier) required in the itinerary, the number of airlines that were used to provide service, and the number of changes required to a different airline (interlines). For each of these variables the higher the variable the lower the quality of service. Figure 4.2 displays the patterns of one way trips over the sample period while the patterns of round trip itineraries are shown in Figure 4.3. For one way tickets $28 \%$ of the tickets used more than one airline on a trip in 
1979I. By 1992IV only $4 \%$ of the one way itineraries required that passengers interline. There is little change in number of segments over the study period. The pattern for round trip tickets is similar. In 1979I nearly half of the round trip itineraries involved more than one airline. Some of these involved more than one interline as an itinerary started with one carrier, switched to a second, then went back to the first carrier on the return. There is a slight increase in the number of segments indicating that while passengers were not decreasing the number of segments over the study period they were switching to preferred itineraries on the same airline. This is what would be expected under hub-and-spoke systems.

In summary, the itinerary data suggest that there has been some improvement in the quality of service over the study period. If ignored in the computation of price indices these service quality improvements would artificially inflate the rate of growth in prices.

\subsection{Flight Convenience and Availability}

Passengers typically have clear preferences regarding the time of travel and location of departure. They may choose the expected time of departure or the time of arrival at the final or intermediate destination. The willingness to accept other flight times or locations vary a great deal with trip purpose. Ideally, we would measure when and where the passenger wanted to leave and when and where the passenger left. This is not possible. Instead we proxy this aspect of flight convenience and availability with a hedonic characteristic of service quality measured as the number of departures at the airport of origin. We use the total scheduled departures from DOT'S Airport Activity Statistics Form 41 Schedule T3 to measure departures. The more departures that occur (higher flight frequency), the more likely that the time of departure will match the most desired time for the passenger and consequently indicates a higher level of service.

The number of flights at different size airports has changed since deregulation when airlines were allowed to offer service at some airports and eliminate service to other airports, typically those serving small communities. The pattern of change in departures for different sizes of airports are displayed in Figure 4.4. The group of large airports is represented by the twenty airports with the highest total departures between 1979 and 1992. The medium airports are represented by the twenty airports ranked between 100 and 119 in terms of total departures. Small airports are represented by those ranked between 300 and 319 and very small airports are represented by the twenty airports

ranked between 400 and 419 . Departures increased by $34 \%$ over the study period for large airports, by $20 \%$ for medium and small airports while departures decreased by $80 \%$ for very small airports. There was a clear shift from very small to larger cities. From the airline's perspective the shift was economical since offering service to very small airports that service small municipalities was an expensive proposition when few enplanements could be expected. However, from the passenger's perspective offering service to small 
communities was desirable since it reduced travel time to an alternative city's airport. For our study, we view departures from small communities as an indication of high service quality and a corresponding willingness of passengers to pay higher prices than they would be willing to pay at the closest medium or large airport.

Another aspect of higher flight frequency, however, is higher congestion and an increased likelihood of flight delay. This suggests that at some point, higher flight frequency has negative consequences on passenger convenience. Since more tickets are likely to be generated at airports that have high flight frequencies, the impact of the congestion and flight delay consequences of flight frequency are likely to be more apparent in our sample than aspects that represent convenience.

\subsection{Passenger Amenity}

We use hedonic characteristics to measure two dimensions of passenger amenity: food, and class of service. First class service brings with it an array of amenities, among them more space, priority boarding, more attentive service, and a better meal. Class of service is information directly provided for each itinerary in DB1A and thus we know when a particular segment of the itinerary is first class or business class. We construct a dummy variable for this class of service (FirstCl). For carriers that offer only one class of service, typically new entrants, all tickets are reported as first class, even though the characteristics of service more closely resemble coach. Consequently, we have constructed the dummy variable (FCNew) to indicate first class service on carriers which only designate one class of service for their itineraries during the quarter. It is difficult to differentiate this service with a coach ticket designation.

When no-frills airlines began offering service, one of the amenities they most visibly compromised was airline food. It seems clear that the more an airline spends on food the higher will be the quality of service received by consumers and the more they would be willing to pay for service. We obtain information on a carrier's food expenditures from Form 41 Schedule P6 and standardize it by the number of enplanements during that quarter. We then construct an itinerary specific measure by adding the food cost per enplanement for each airline providing service for each segment in the itinerary to measure this service quality characteristic (Food). We also experimented with using the airlines expenditures per passenger mile for proxying food service. This yielded very similar results. In either case, our use of food expense on the itinerary proxies several amenities that are also correlates of food expense in our model. An airlines willingness to spend money on food often indicates a willingness to provide many more amenities.

Figure 4.5 indicates there has been a gradual increase in food expenditures per passenger. Even when one controls for inflation in food prices, we find real expenditures per passenger increased by about $25 \%$ during the sample period. If food expenditures were simply passed through, it would indicate that about $3 \%$ of the price of travel, on 
average, could be attributed to food expense. This figure masks the large variability in food expenses across airlines. Some carriers, for example Pan Am, spent nearly twenty dollars per passenger on average prior to their merger with National. Low cost carriers like Southwest Airlines spend almost nothing on passenger food.

\subsection{Ticket Restrictions}

A major feature of airline fare structures is ticket restrictions. These may shift the risk of nontravel from airlines to consumers (non-refundability), provide the airlines with improved predictability about demand (advanced booking), or enhance the airline's ability to use price discrimination information separating price sensitive consumers from business travelers with more inelastic demands (Saturday night stay-overs). A major liability of our use of DOT's DB1A as the primary source of ticket information is that it includes very limited information on ticket restrictions. What can be consistently identified from the fare class codes is that some kind of restriction was used on a particular ticket leading to the ticket being discounted. However, are unable to identify what the restriction is. Figure 4.6 shows the fraction of all tickets which were discounted coach tickets for one way and round trip travel during the sample period. The data show a steady increase in both one way and round trip tickets that are discounted coach. For round trip tickets, only $30 \%$ of tickets were discounted coach in 1979I, increasing to nearly $90 \%$ by $1992 \mathrm{IV}$.

Yield management practices on the part of airlines add further complications to the discounting process. While two airlines may offer service with an identical fare, their fare structure may be very different because they offer different numbers of seats at that fare. Consequently, it would be inappropriate to model the situation as though the fare described the price at the margin of an individual's willingness to accept the particular restriction. Because of the unavailability of different fares, consumers typically will meet the requirements for higher sets of fare restrictions than those actually required by their ticket. For example, a consumer may meet the 30 day book in advance, no refund, Saturday night stay restrictions, but because this fare is sold out, they may accept a 14 day book in advance, no refund, with a Saturday night stay fare.

\subsection{Frequent Flier Programs and Zero Coupon Tickets}

Frequent flyer miles were introduced in the mid 1980s by then CEO Robert Crandall of American Airlines. The purpose behind this program was to increase customer loyalty by offering them free travel at a later date. The program has proliferated to other industries. Grocery stores now offer discounts for frequent shoppers. The CPI currently ignores zero coupon tickets. The pattern of these tickets from 1979 to 1992 can be seen in Figure 4.7 for one way and round trip travel. For both round trip and one way travel 
there is a spike in 1987 associated with the introduction of these tickets to about 10 percent for both one way and round trip travel. By 1988, these decline to about $5 \%$ of round trip travel and about $4 \%$ of one way trips.

The use of zero coupon tickets by consumers is determined by a mix of expectations about their value and the rules that a carrier has for their redemption. During periods of increasing prices we see an increased use of free tickets. An implication of consumers choosing when and where to use zero coupon tickets is the price that would have been paid for a zero coupon itinerary tends to be more than the price for the typical itinerary. In other words, zero coupon tickets tend to go to more exotic places (trip to Hawaii rather than to Florida) than other trips.

During the period of our study, zero coupon tickets were generated solely by air travel, indicating that they should be used to adjust the effective price of air travel. This view is seriously blurred when, for example, credit card and long distance phone companies began offering frequent flyer miles as part of the inducement to use their services. This raises the issue about where they should be included in the CPI: as adjustments to air travel or the services that generated the frequent flier miles. While conceptually it makes sense to adjust the price of the service that generated the benefit, this is certainly beyond the scope of this paper. It would require that we partition benefits earned by travel from benefits earned by other means and to constantly revise the value of those benefits based on expectations about future air travel prices, the usefulness of the miles based on an airlines network or partnership arrangements, and anticipations about the airlines redemption policy. Instead we adopt an alternative approach that allocates all of the benefits of frequent flier programs to reductions in the price of air travel. We impute the value of zero coupon tickets by our hedonic equation and then construct an expenditure adjustment factor:

$$
\lambda=\frac{\text { value of tickets purchased }}{\text { value of tickets used }}
$$

The result of this adjustment factor is to lower the effective price index in quarters where a large number of zero coupon tickets were used rather than the quarter where the ticket is earned. ${ }^{3}$

\footnotetext{
${ }^{3}$ We recognize that our approach is not perfect with respect to zero coupon tickets in at least three dimensions. First, there are zero coupon tickets which are systematically excluded from our analysis. Because we use DB1A as our source of information, we do not have consistent information about foreign travel (DB1A includes only those trips which incorporate a trip segment within the US). Consequently, because of data limitations, we suspect that the most expensive zero coupon tickets are systematically left out of the analysis. The portion of international zero coupon tickets is most likely higher than the portion of domestic zero coupon tickets so our analysis systematically overestimates the price, even of domestic travel. Of lesser importance, passenger upgrades offered as part of a frequent flier program may also systematically be left out of our analysis if they are not explicitly recorded (passengers get a higher quality of service than we have recorded on their itinerary). To the extent that these two
} 


\subsection{Route Specific Factors}

Several route characteristics clearly affect the price of travel. Not the least of these is the distance between the origin and destination. Other variables which many have attempted to incorporate into modeling the demand side of long distance travel include weather related variables such as mean temperature difference in an attempt to capture vacation travel in the winter months. Others have included variables which attempt to capture the demand for business travel such as the number of white collar jobs in an area. In our model we assume that these factors are either very slow to change or that they are strongly correlated with other factors in our model (for example, white collar jobs are likely correlated with per capita income). We capture these slowly moving factors with fixed route specific effects which describe the origin-destination pair. In our model this amounts to approximately 115,000 route effects for the one way models and 134,000 for the round trip models.

\subsection{Other Factors}

We also considered the use of other factors. These included safety, circuity of travel, complaint data, and controls for local demand characteristics such as growth of local gdp and employment rates at origin and destination. Safety was excluded primarily because there is very little data on safety. Aside from the extremely rare event of an actual crash, there is no database that tracks mechanical failures, expenditures on security, etc. Even if changes in security could be tracked, the likelihood is that the security procedures were mandated by unmeasurable increases in security risks. Circuity of travel, defined as the ratio of actual miles flown to the minimum flight length of the route, was included in some models, but did not perform as well as the number of flight segments. Complaint data was not used because the data are driven by expectations. Persons who expect poor service rarely find it worthwhile to complain when they get it. Local demand factors were excluded for several reasons. With over 115,000 route pairs, collecting local economic data is daunting. Additionally, there is no theoretical reason for regional economic factors to enter into consumer demand equations such as the hedonic index. Combining these facts with significant uncertainty as to usefulness led us to exclude local demand factors from our model.

\section{Results}

Our intended question is how do alternative methodologies to those BLS currently utilizes affect the Air Fare Index. This requires that we simulate their current methodology

factors are important, data limitations suggest that we will not fully capture the effects of frequent flier programs in our adjusted price index. 
over the study period, without the advantage of using their data. We then compare these results to price indices which allow for increased substitutability in market baskets by using sales information and adjust the price index by holding attributes of service quality fixed. These different indices are summarized in Table 5.1.

The replicated airfare indices for arithmetic and geometric means and the airfare index calculated by the BLS are presented in Figure 5.1. The replicated indices match fairly well with the actual index reported by the BLS. What differences there are between the replicated arithmetic mean series and the replicated geometric mean series are in the direction expected. The replicated arithmetic mean series, with weights that are not entirely fixed, has a higher rate of inflation (average annual inflation is 10.19 $\%$ ). While the replicated geometric mean series, also with weights that are not entirely fixed, has a lower rate of inflation (average annual inflation is $8.84 \%$ ). This supports the general notion that geometric means lead to lower estimates of inflation.

As we noted in the last section we consider one way and round trip tickets to have key differences in terms of both the passenger and the airline. Consequently, we also develop separate demand models for one way and round trips and discuss these results before combining them in an overall air travel demand model. We first estimate a base model that does not include any aspects of service quality:

$$
\ln P_{i j t}=\alpha_{i}+\beta_{t} D_{t}+\varepsilon_{i j t}
$$

for ticket $i$ on route $j$ at time $t . \beta_{t}$ is the coefficient on a dummy time variable where the reference category is time period 1979I. Omitted service quality characteristics may be correlated with fixed time and/or route effects and thus the ordinary least squares estimates of the $\alpha_{i}^{\prime} s$ and the $\beta_{t}^{\prime} s$ may be biased and inconsistent. The predicted price ratio from 1979I to time $\mathrm{t}$ is:

$$
\frac{P_{i t}}{P_{i, 1979 I}}=\frac{\exp \left(\alpha_{i}+\beta_{t}\right)}{\exp \left(\alpha_{i}+0\right)}=\exp \left(\beta_{t}\right)
$$

The estimates for the one way and round trip models are provided in Table 5.2. Summary statistics including the number of observations, $N$, and the number of route city pairs, $N_{i}$, are also listed. The relatively high $R^{2}$ values given such disaggregated data reveal the substantial explanatory power associated with these fixed route characteristics.

The results of this basic model are useful. While they do not adjust for the characteristics of service they do provide a comparison between our method which provides for changing weights among ticket types as opposed to the constant weights used in the BLS consumer price index. This is particularly important because the BLS index has fixed proportions of heavily discounted tickets while our analysis shows that these proportions change substantially over time. 
Our hedonic model includes the effects of restrictions and service quality

$$
\ln P_{i j t}=\alpha_{i}+\beta_{t} D_{t}+\sum_{k} \gamma_{t} X_{k i j t}+\varepsilon_{i j t}
$$

where the $X_{k i j t}$ are the $k$ measures of service quality and ticket discounting for ticket $i$ on route $j$. In this model we control for the expenditures on food, the number of departures, the number of segments (more segments indicating a more circuitous trip and required changes of planes), interlining (the requirement that passengers also change airlines when they change planes), the class of service (dummy indicating first class) and whether or not the ticket had fare restrictions. Food, interlining and departures are incorporated in logged form. Parameter estimates for this model are presented in Table 5.3.

The signs and magnitudes for the coefficients on food and first class service are as expected. Also, restrictions and discounting lower the price of the ticket. The coefficients on other aspects of service quality remain substantively similar across models. Restrictions mostly affect the price of round trip tickets (where Saturday night stayovers can be enforced) and have relatively little effect on one way trips: lowering the price of one way trips by approximately $15 \%$ and the price of round trip tickets by approximately $30 \%$. These reductions hold regardless of class of the ticket (first class or coach).

To generate prices indices for the base and hedonic models, it is necessary to aggregate the one way and roundtrip price indices. This is accomplished by taking their expenditure weighted geometric mean value:

$$
\frac{P_{t}}{P_{t-1}}=\left(\frac{\beta_{t}^{1}}{\beta_{t-1}^{1}}\right)^{k_{t}^{1}}\left(\frac{\beta_{t}^{2}}{\beta_{t-1}^{2}}\right)^{k_{t}^{2}}
$$

where $\beta_{t}^{1}$ and $\beta_{t}^{2}$ are coefficients based on one way and the roundtrip tickets, respectively, and $k_{t}^{1}$ and $k_{t}^{2}$ are the expenditure shares of one way and roundtrip tickets, respectively. We have constructed these indices for the base model and the hedonic model. The results are presented in Figure 5.2.

Finally, we turn to adjusting the indices based on the base model and our hedonic model for zero coupon tickets. Since we have imputed values associated with all zero coupon tickets, we can use this to deflate the effective price. The indices generated by our base and hedonic regression models are presented in Figure 5.3

Comparing these indices with the hedonic index leads to an interesting conclusion. The hedonic index has an average annual inflation of $6.27 \%$. This is much lower than any of the other indices. Specifically, the difference between the replicated indices and the hedonic index is much larger than the difference between the replicated indices and 
the actual CPI index. This seems to imply that quality adjustment issues are more important to correcting upward biases in the airfares index than both fixed weight/basket and aggregation issues. However, this result is directly contradicted by our bench mark regression. The bench mark regression estimates a simple fixed effects model with time dummies but no quality variables. The average annual inflation resulting from this model is $4.42 \%$ indicating that adjusting for quality increases inflation by a small amount. The appropriate conclusion can only be that quality fell during the period 1979 to 1992. Also, the difference between the replicated indices and the bench mark hedonic index is much larger than the difference between the bench mark hedonic index and the hedonic index with quality variables. This suggests that having a market basket determined by sales in each period (and appropriately aggregating) lowers inflation much more than adjusting for quality raises inflation. Thus substitution bias is more important than quality bias in our sample period. One reason may be the very small amount of routes included in the BLS market basket (approximately 670). The DB1A data set can identify over 134,000 different routes in the sample period. It is unlikely that all substitution biases are dealt with when the consumer can only substitute among $0.5 \%$ of the total routes. Quality adjustments are still important in order to avoid all bias (in this case downward bias). It seems likely that this fact would hold for many of the subindices that make up the CPI (especially indices tracking service oriented industries and high-tech appliances). Thus, complete correction of bias in the CPI (upward or downward) may not be attainable without methods to more accurately control for quality.

\section{Conclusions}

In our research we have attempted to take an exhaustive approach to measurement issues in price index construction for the BLS airfare index. While our findings are constrained by data availability and other resource constraints that may not be as constraining for government agencies, we have nonetheless been able to pursue a number of the objectives for dealing with the biases that the 1997 CPI Commission recommended be addressed. We have also provided a detailed protocol for data collection and analysis that can be replicated and can be enhanced by availability of additional data sources. We find an upward bias in the BLS airfare index over the period considered. However, we also have found that the data and computational resources required to implement the Commission recommendations for the airline industry, one which for historical reasons has a substantial amount of detailed data, is quite onerous and the corrections via the hedonic approach are not without their own problems. Because of issues of practicality and implementability, the goals of the Commission recommendations remain illusive and problematic. 


\section{References}

Abraham, Katharine; John S. Greenlees and Brent R. Moulton (1998), "Working to Improve the Consumer Price Index," The Journal of Economic Perspectives, 12:27-36

Armknecht, Paul A. and Daniel H. Ginsburg (1992), "Improvements in Measuring Price Changes in Consumer Services: Past, Present, and Future," in Output Measurement in the Service Sectors, Zvi Griliches ed. Chicago, IL: University of Chicago Press.

Baker, Dean (1998), Getting Prices Right: The Debate Over the Consumer Price Index. Armonk, NY: M. E. Sharpe, inc.

Boskin, Michael J., Ellen R. Dulberger, Robert J. Gordon, Zvi Griliches, and Dale W. Jorgenson (1997), "The CPI Commission: Findings and Recommendations," American Economic Review Papers and Proceedings, 87:78-83.

Boskin, Michael J., Ellen R. Dulberger, Robert J. Gordon, Zvi Griliches, and Dale W. Jorgenson (1998), "Consumer Prices, the Consumer Price Index, and the Cost of Living," The Journal of Economic Perspectives, 12:3-26.

Boskin, Michael J. and Dale W. Jorgenson (1997), "Implications of Overstating Inflation for Indexing Government Programs and Understanding Economic Progress," American Economic Review Papers and Proceedings, 87:89-93.

Caves, D., L. R. Christensen, M. W. Tretheway and R. J. Windle (1987), "An Assessment of the Efficiency of U.S. Airline Deregulation via an International Comparison," in Public Regulation: New Perspectives on Institution and Policies, E. E. Bailey, ed. Cambridge: MIT Press.

Deaton, Angus (1998), "Getting Prices Right: What should be Done?" The Journal of Economic Perspectives, 12:37-46

Diewert, W. Erwin (1998), "Index Number Issues in the Consumer Price Index," The Journal of Economic Perspectives, 12:47-58

Färe, R., S. Grosskopf, M. Norris, and Z. Zhang (1994), "Productivity Growth, Technical Progress and Efficiency Change in Industrialized Countries," American Economic Review, 84:66-83.

Gordon, Robert J. and Zvi Griliches (1997), "Quality Change and New Products," American Economic Review Papers and Proceedings, 87:84-88.

Griliches, Zvi (1961), "Hedonic Price Indexes for Automobiles: An Econometric Analysis of Quality Change" in Price Statistics of the Federal Government, U.S. Government Printing Office, Washington, D.C.

Jeon, B. M., and Robin C. Sickles (2004), "The Role of Environmental Factors in Growth Accounting," Journal of Applied Econometrics, 19, 567-591.

Morrison, S. A. and C. Winston (1995). The Evolution of the Airline Industry. Washington, D.C., Brookings Institution.

Nordhaus, William D. (1998), "Quality Change in Price Indexes," The Journal of Economic Perspectives, 12, 59-68 
Pakes, Ariel (2003) "A Reconsideration of Hedonic Price Indices With An Application to PC's," The American Economic Review, 93:1578-96

Pakes, Ariel (2005), "Hedonics and the Consumer Price Index," forthcoming in Les Annales d'Economie et de Statistique.

Perloff, Jeffrey, Robin C. Sickles, and Jesse C. Weiher (2003), "An Analysis of Market Power in the U. S. Airline Industry, in Measuring Market Power, edited by D. Slottje, Amsterdam: North-Holland, 309-323.

Pollak, Robert A. (1998), "The Consumer Price Index: A Research Agenda and Three Proposals," The Journal of Economic Perspectives, 12, 69-78.

Primont, Diane F. and Mary F. Kokoski (1990), "Comparing Prices across Cities: A Hedonic Approach," Bureau of Labor Statistics Working Paper \#: 204.

Quigley, John M.(1982), "Nonlinear Budget Constraints and Consumer Demand: An Application to Public Programs for Residential Housing," Journal of Urban Economics, 12:177-201.

Ridker, Ronald G. and John A. Henning (1992), "The Determinants of Residential Property Values with Special Reference to Air Pollution," The economics of the environment, 368-379. (Originally published 1967 in Review of Economics and Statistics).

Rosen, S. (1974), "Hedonic Prices and Implicit Markets: Product Differentiation in Pure Competition," Journal of Political Economy, 82, 34-55.

Schwartz, Amy Ellen and Benjamin P. Scafidi (2000), "Quality Adjusted Price Indices for Four Year Colleges," mimeo, New York University and Georgia State University.

Trajtenberg, Manuel (1990), Economic analysis of product innovation: The case of CT scanners, Cambridge, Harvard University Press.

Triplett, J. E. (1984), "Measuring Technological Change with Characteristics-Space Technique," BLS Working Papers \# 141.

Triplett, J. E. (2004), "Handbook on Hedonic Indexes and Quality Adjustments in Price Indexes: Special Application to Information Technology Products," Brookings Institution, Washington, D.C. 


\begin{tabular}{|c|c|c|c|c|c|c|}
\hline & BLS & DBIA & DB1A & Bench Mark & Hedonic & Hedonic \\
\hline & Airfare & Arithmetic & Geometric & Hedonic & Index w/o & Index w/ \\
\hline & Index & Mean & Mean & Model & Restrictions & Restrictions \\
\hline Data Source & SABRE & DB1A & DB1A & DB1A & DB1A & DB1A \\
\hline Fixed Route & Yes & Yes & Yes & No & No & No \\
\hline Fixed Class & Yes & No & No & No & No & No \\
\hline Fix Wgt. Area & Yes & No & No & No & No & No \\
\hline Fix Wgt. U.S. & Yes & Yes & Yes & No & No & No \\
\hline Geo Mean & No & No & Yes & NA & NA & NA \\
\hline Arith Mean & Yes & Yes & No & NA & NA & NA \\
\hline Quality Adj. & No & No & No & Yes & Yes & Yes \\
\hline Zero Coup Adj. & No & No & No & Yes & Yes & Yes \\
\hline Inf. w/o Zero Adj & - & - & - & $4.82 \%$ & $5.11 \%$ & $6.71 \%$ \\
\hline Avg. Inf. & $9.80 \%$ & $10.19 \%$ & $8.84 \%$ & $4.42 \%$ & $4.69 \%$ & $6.27 \%$ \\
\hline \multicolumn{7}{|c}{ Table 5.1: A Comparison of Different Indices } \\
\end{tabular}




\begin{tabular}{|c|c|c|c|c|c|c|c|c|c|}
\hline \multirow[b]{2}{*}{ Coeff } & \multicolumn{2}{|c|}{$\begin{array}{c}\text { One Way } \\
\text { Model }\end{array}$} & \multicolumn{2}{|c|}{$\begin{array}{c}\text { Round Trip } \\
\text { Model }\end{array}$} & \multirow[b]{2}{*}{ Coeff } & \multicolumn{2}{|c|}{$\begin{array}{c}\text { One Way } \\
\text { Model }\end{array}$} & \multicolumn{2}{|c|}{$\begin{array}{c}\text { Round Trip } \\
\text { Model }\end{array}$} \\
\hline & Estimate & Std Error & Estimate & Std Error & & Estimate & Std Error & Estimate & Std Error \\
\hline 1979-1 & .000000 & .000000 & .000000 & .000000 & $1987-1$ & .531658 & .000669 & .336607 & .000587 \\
\hline $1979-2$ & .131647 & .000717 & .084386 & .000627 & $1987-2$ & .557406 & .000660 & .327748 & .000576 \\
\hline $1979-3$ & 183385 & .000703 & .120222 & .000634 & $1987-3$ & .642275 & .000653 & .397713 & .000582 \\
\hline $1979-4$ & .271259 & .000688 & .238698 & .000630 & $1987-4$ & .702656 & .000667 & .455133 & .000584 \\
\hline 1980-1 & .341144 & .000699 & .326022 & .000638 & 1988-1 & .750258 & .001217 & .655742 & .001002 \\
\hline $1980-2$ & .368445 & .000677 & .330174 & .000636 & $1988-2$ & 684097 & .000659 & .502266 & .000571 \\
\hline $1980-3$ & 347191 & .000677 & .303250 & .000648 & 1988-3 & .776370 & .001141 & 686379 & .001008 \\
\hline 1980-4 & .323089 & .000712 & .318564 & .000639 & $1988-4$ & .686545 & .000669 & .516745 & .000574 \\
\hline 1981-1 & .406969 & .000703 & .473544 & .000666 & 1989-1 & .875029 & .001078 & .907902 & .000929 \\
\hline $1981-2$ & .391012 & .000679 & .421443 & .000647 & $1989-2$ & .666478 & .000658 & .567267 & .000573 \\
\hline $1981-3$ & .366208 & .000673 & .423067 & .000669 & 1989-3 & .566361 & .000648 & .494588 & .000570 \\
\hline $1981-4$ & .341781 & .000683 & .418745 & .000644 & $1989-4$ & .596645 & .000661 & .510470 & .000562 \\
\hline $1982-1$ & .341514 & .000682 & .387478 & .000651 & 1990-1 & .647923 & .000664 & .600511 & .000567 \\
\hline $1982-2$ & .361650 & .000667 & .409308 & .000636 & $1990-2$ & .676124 & .000655 & 598749 & .000561 \\
\hline $1982-3$ & .389378 & .000659 & .454254 & .000640 & 1990-3 & .651849 & .000654 & .540321 & .000563 \\
\hline $1982-4$ & .376822 & .000682 & .409182 & .000632 & $1990-4$ & .700685 & .000672 & .581347 & .000569 \\
\hline $1983-1$ & .375201 & .000679 & .345801 & .000629 & $1991-1$ & .619265 & .000674 & .654331 & .000577 \\
\hline $1983-2$ & .438298 & .000657 & .440545 & .000624 & $1991-2$ & .611315 & .000662 & .570308 & .000563 \\
\hline $1983-3$ & .450713 & .000649 & .509589 & .000643 & $1991-3$ & .660826 & .000655 & .585231 & .000570 \\
\hline 1983-4 & .448037 & .000655 & .530297 & .000628 & $1991-4$ & .670174 & .000669 & .636296 & .000570 \\
\hline 1984-1 & .480502 & .000659 & .557338 & .000630 & $1992-1$ & .687399 & .000668 & .757830 & .000582 \\
\hline 1984-2 & 491375 & .000645 & .530916 & .000608 & $1992-2$ & 646160 & .000658 & .543558 & .000565 \\
\hline $1984-3$ & .473786 & .000640 & .510774 & .000618 & $1992-3$ & .641092 & .000652 & .427392 & .000559 \\
\hline $1984-4$ & .498520 & .000646 & .501107 & .000608 & $1992-4$ & .671827 & .000661 & .634672 & .000572 \\
\hline 1985-1 & .500758 & .000651 & .487270 & .000608 & & & & & \\
\hline $1985-2$ & .508989 & .000638 & .413476 & .000595 & $\begin{array}{l}\mathrm{R} 2 \\
\mathrm{~F}\end{array}$ & & $\begin{array}{l}.08112 \\
113511\end{array}$ & & 40185 \\
\hline $1985-3$ & .505568 & .000636 & .438910 & .000604 & $\mathrm{~F}$ & & $\begin{array}{l}111,511 \\
64024141\end{array}$ & & $\begin{array}{l}120,919 \\
95279537\end{array}$ \\
\hline $1985-4$ & .423235 & .000635 & .425652 & .000601 & $\begin{array}{l}\mathrm{N} \\
\mathrm{Ni}\end{array}$ & & $\begin{array}{l}\text { 64,024,141 } \\
79,248\end{array}$ & & $\begin{array}{l}79,2 / 9,53 / \\
79,139\end{array}$ \\
\hline $1986-1$ & .429316 & .000637 & .365051 & .000593 & & & & & \\
\hline $1986-2$ & .386636 & .000641 & .326974 & .000594 & & & & & \\
\hline $1986-3$ & .454321 & .000628 & .332452 & .000605 & & & & & \\
\hline $1986-4$ & .493267 & .000653 & .386131 & .000597 & & & & & \\
\hline
\end{tabular}

Table 5.2 


\begin{tabular}{|c|c|c|c|c|c|c|c|c|c|}
\hline \multirow[b]{2}{*}{ Coeff } & \multicolumn{2}{|c|}{$\begin{array}{c}\text { One Way } \\
\text { Model }\end{array}$} & \multicolumn{2}{|c|}{$\begin{array}{l}\text { Round Trip } \\
\text { Model }\end{array}$} & \multirow[b]{2}{*}{ Coeff } & \multicolumn{2}{|c|}{$\begin{array}{c}\text { One Way } \\
\text { Model }\end{array}$} & \multicolumn{2}{|c|}{$\begin{array}{c}\text { Round Trip } \\
\text { Model }\end{array}$} \\
\hline & Estimate & Std Error & Estimate & Std Error & & Estimate & Std Error & Estimate & Std Error \\
\hline In Food & .057350 & .000062 & .070076 & .000122 & 1986-1 & 445976 & .000632 & .401204 & .000579 \\
\hline ln Dep & -.077457 & .000210 & -.021254 & .000186 & 1986-2 & 413581 & .000636 & .366409 & .000580 \\
\hline ln Inter & .319661 & .000547 & .314721 & .000194 & 1986-3 & .477949 & .000624 & .373821 & .000591 \\
\hline First Cl & .009840 & .000249 & .622013 & .000346 & 1986-4 & .519626 & .000648 & .430882 & .000582 \\
\hline 2 Segs & .004774 & .000221 & & & 1987-1 & .553903 & .000664 & .383329 & .000573 \\
\hline 3 Segs & & & .000617 & .000217 & $1987-2$ & .582817 & .000656 & .383257 & .000564 \\
\hline 4 Segs & & & -.109097 & .000208 & $1987-3$ & .662000 & .000649 & .447529 & .000571 \\
\hline 1979-1 & .000000 & .000000 & .000000 & .000000 & 1987-4 & .724473 & .000662 & .503507 & .000573 \\
\hline $1979-2$ & .119343 & .000708 & .072007 & .000607 & 1988-1 & .740659 & .001205 & .681558 & .000975 \\
\hline $1979-3$ & .177663 & .000695 & .111818 & .000614 & 1988-2 & .721165 & .000654 & .549343 & .000561 \\
\hline 1979-4 & .267474 & .000680 & .230940 & .000610 & 1988-3 & .768125 & .001130 & .707544 & .000982 \\
\hline 1980-1 & .333729 & .000691 & .317276 & .000619 & $1988-4$ & .729768 & .000665 & .562544 & .000566 \\
\hline $1980-2$ & .355464 & .000670 & .321492 & .000617 & 1989-1 & .862361 & .001068 & .908509 & .000906 \\
\hline 1980-3 & .332617 & .000670 & .298420 & .000629 & 1989-2 & .701687 & .000653 & .604131 & .000565 \\
\hline $1980-4$ & .288215 & .000705 & 311909 & .000621 & 1989-3 & .606047 & .000644 & .536835 & .000562 \\
\hline 1981-1 & .375977 & .000695 & .457073 & .000647 & $1989-4$ & 634399 & .000656 & .545739 & .000555 \\
\hline $1981-2$ & .365019 & .000672 & 423952 & .000628 & 1990-1 & .678261 & .000662 & .629540 & .000562 \\
\hline $1981-3$ & .330924 & .000667 & 420699 & .000651 & 1990-2 & .715318 & .000655 & .631447 & .000558 \\
\hline $1981-4$ & .305416 & .000677 & .413868 & .000627 & $1990-3$ & .685130 & .000654 & .570096 & .000562 \\
\hline 1982-1 & .309437 & .000675 & .382742 & .000633 & $1990-4$ & .738359 & .000672 & .611860 & .000566 \\
\hline $1982-2$ & .336192 & .000661 & .422916 & .000618 & 1991-1 & .651171 & .000673 & .682229 & .000574 \\
\hline $1982-3$ & .361963 & .000653 & .462897 & .000623 & $1991-2$ & .643303 & .000663 & .603464 & .000562 \\
\hline $1982-4$ & .351123 & .000675 & .426553 & .000615 & 1991-3 & .696390 & .000657 & .615449 & .000571 \\
\hline 1983-1 & .348629 & .000673 & .363538 & .000612 & 1991-4 & .714363 & .000670 & .666161 & .000569 \\
\hline 1983-2 & .411501 & .000651 & .462283 & .000607 & 1992-1 & .732743 & .000670 & .778981 & .000582 \\
\hline 1983-3 & .426179 & .000643 & .531412 & .000625 & $1992-2$ & .692213 & .000660 & .573328 & .000565 \\
\hline 1983-4 & .417013 & .000649 & .546810 & .000611 & $1992-3$ & .695754 & .000656 & .462976 & .000559 \\
\hline 1984-1 & .453261 & .000654 & .569750 & .000613 & 1992-4 & .722949 & .000664 & .667230 & .000571 \\
\hline 1984-2 & .466200 & .000640 & .549884 & .000593 & & & & & \\
\hline 1984-3 & .448623 & .000635 & .531523 & .000602 & $\begin{array}{l}\mathrm{R} 2 \\
\mathrm{~F}\end{array}$ & & $\begin{array}{l}8254 \\
3347\end{array}$ & & $\begin{array}{l}48334 \\
72030\end{array}$ \\
\hline $1984-4$ & .480478 & .000640 & .525912 & .000592 & $\begin{array}{l}\mathrm{F} \\
\mathrm{N}\end{array}$ & & $\begin{array}{l}3,347 \\
, 024,141\end{array}$ & & $\begin{array}{l}22,150 \\
75,279,542\end{array}$ \\
\hline 1985-1 & .482905 & .000645 & .511242 & .000592 & $\mathrm{Ni}$ & & 248 & & 79,139 \\
\hline $1985-2$ & .494214 & .000633 & .446156 & .000579 & & & & & \\
\hline $1985-3$ & .523423 & .000631 & .471529 & .000589 & & & & & \\
\hline $1985-4$ & .442321 & .000629 & .460142 & .000586 & & & & & \\
\hline
\end{tabular}

Table 5.3 


\begin{tabular}{|c|c|c|c|c|c|c|c|c|c|}
\hline \multirow[b]{2}{*}{ Coeff } & \multicolumn{2}{|c|}{$\begin{array}{c}\text { One Way } \\
\text { Model }\end{array}$} & \multicolumn{2}{|c|}{$\begin{array}{c}\text { Round Trip } \\
\text { Model }\end{array}$} & \multirow[b]{2}{*}{ Coeff } & \multicolumn{2}{|c|}{$\begin{array}{c}\text { One Way } \\
\text { Model }\end{array}$} & \multicolumn{2}{|c|}{$\begin{array}{c}\text { Round Trip } \\
\text { Model }\end{array}$} \\
\hline & Estimate & Std Error & Estimate & Std Error & & Estimate & Std Error & Estimate & Std Error \\
\hline ln Food & .035667 & .000064 & .073075 & .000119 & $1986-1$ & .550154 & .000623 & .562686 & .000569 \\
\hline ln Dep & -.069821 & .000205 & -.025848 & .000181 & $1986-2$ & .523665 & .000628 & .536447 & .000571 \\
\hline ln Inter & .311014 & .000536 & .282482 & .000190 & 1986-3 & .578357 & .000616 & .540619 & .000581 \\
\hline First Cl & .450880 & .000510 & .511057 & .000467 & $1986-4$ & .621167 & .000639 & .602813 & .000573 \\
\hline FCNew & -.746571 & .000601 & .079969 & .000920 & $1987-1$ & .656667 & .000654 & .545567 & .000564 \\
\hline F Restrt & -.163372 & .000917 & -.336050 & .000863 & $1987-2$ & .685043 & .000647 & .550922 & .000555 \\
\hline Y Restrt & -.143883 & .000135 & -.294731 & .000134 & $1987-3$ & .769153 & .000640 & .619987 & .000562 \\
\hline 2 Segs & .004774 & .000221 & & & $1987-4$ & .821586 & .000652 & .675525 & .000564 \\
\hline 3 Segs & & & -.002569 & .000211 & 1988-1 & .763661 & .001179 & .671467 & .000950 \\
\hline 4 Segs & & & -.108666 & .000202 & $\begin{array}{l}1988-1 \\
1988-2\end{array}$ & . .810117 & .000644 & 年 .722428 & .000950 \\
\hline 1979-1 & .000000 & .000000 & .000000 & .000000 & 1988-3 & .798768 & .001106 & .697766 & .000957 \\
\hline $1979-2$ & .130343 & .000693 & .085149 & .000592 & $1988-4$ & .809356 & .000654 & .736161 & .000557 \\
\hline 1979-3 & .194426 & .000680 & .127450 & .000598 & $1989-1$ & .876850 & .001046 & .878056 & .000883 \\
\hline 1979-4 & .276723 & .000665 & .240001 & .000595 & $1989-2$ & .783943 & .000653 & .766493 & .000555 \\
\hline 1980-1 & .344044 & .000676 & .310714 & .0006003 & $1989-3$ & 684838 & .000643 & .709309 & .000553 \\
\hline $1980-2$ & .383116 & .000656 & .324051 & .000601 & $1989-4$ & .711496 & .000645 & .720662 & .000547 \\
\hline 1980-3 & .360788 & .000656 & .311709 & .000613 & $1990-1$ & .862975 & .000657 & .800734 & .000554 \\
\hline $1980-4$ & .321839 & .000690 & .351941 & .000605 & $1990-2$ & .901681 & .000651 & . 807870 & .000551 \\
\hline 1981-1 & .406595 & .000681 & .493380 & .000631 & $1990-3$ & .877281 & .000651 & .749520 & .000554 \\
\hline $1981-2$ & .403843 & .000659 & .474508 & .000612 & $1990-4$ & .930724 & .000668 & .788713 & .000559 \\
\hline 1981-3 & .377461 & .000654 & .475235 & .000635 & 1991-1 & .850231 & .000670 & .863407 & .000566 \\
\hline $1981-4$ & .351862 & .000664 & .471488 & .000611 & $\begin{array}{l}1991-1 \\
1991-2\end{array}$ & $\begin{array}{l}.850231 \\
.844376\end{array}$ & .000659 & $\begin{array}{l}.80340 / \\
.798129\end{array}$ & .000560 \\
\hline $1982-1$ & .359685 & .000662 & .441142 & .000618 & $1991-3$ & .901937 & .000654 & .813627 & .000564 \\
\hline $1982-2$ & .390038 & .000648 & .492552 & .000603 & $1991-4$ & .922502 & .000668 & .858237 & .000563 \\
\hline $1982-3$ & .416864 & .000640 & .540316 & .000608 & & 943008 & & .962937 & .000575 \\
\hline $1982-4$ & .406352 & .000662 & .523693 & .000601 & $\begin{array}{l}1992-1 \\
1992-2\end{array}$ & $\begin{array}{l}.943008 \\
.906864\end{array}$ & .000659 & . .775220 & .000560 \\
\hline 1983-1 & .404044 & .000660 & .463098 & .000598 & $1992-3$ & .910479 & .000654 & .667321 & .000554 \\
\hline 1983-2 & .472558 & .000638 & .563095 & .000593 & $1992-4$ & .941617 & .000663 & .869538 & .000565 \\
\hline $1983-3$ & .488926 & .000631 & .623636 & .000611 & & & & & \\
\hline $1983-4$ & .483680 & .000637 & .657317 & .000598 & R2 & & 0285 & & 49699 \\
\hline 1984-1 & .516296 & .000641 & .667603 & .000599 & F & & 77,380 & & 301,484 \\
\hline 1984-2 & .568221 & .000630 & .677280 & .000581 & $\mathrm{~N}$ & & 4,024,141 & & $95,279,542$ \\
\hline 1984-3 & .557910 & .000625 & .679142 & .000591 & $\mathrm{Ni}$ & & 9,248 & & 79,139 \\
\hline $1984-4$ & .588324 & .000631 & .680385 & .000581 & & & & & \\
\hline $1985-1$ & .585641 & .000635 & .658956 & .000581 & & & & & \\
\hline $1985-2$ & .597059 & .000623 & .596044 & .000568 & & & & & \\
\hline $1985-3$ & .620830 & .000622 & .621574 & .000578 & & & & & \\
\hline $1985-4$ & .551832 & .000622 & .611416 & .000576 & & & & & \\
\hline
\end{tabular}

Table 5.4 


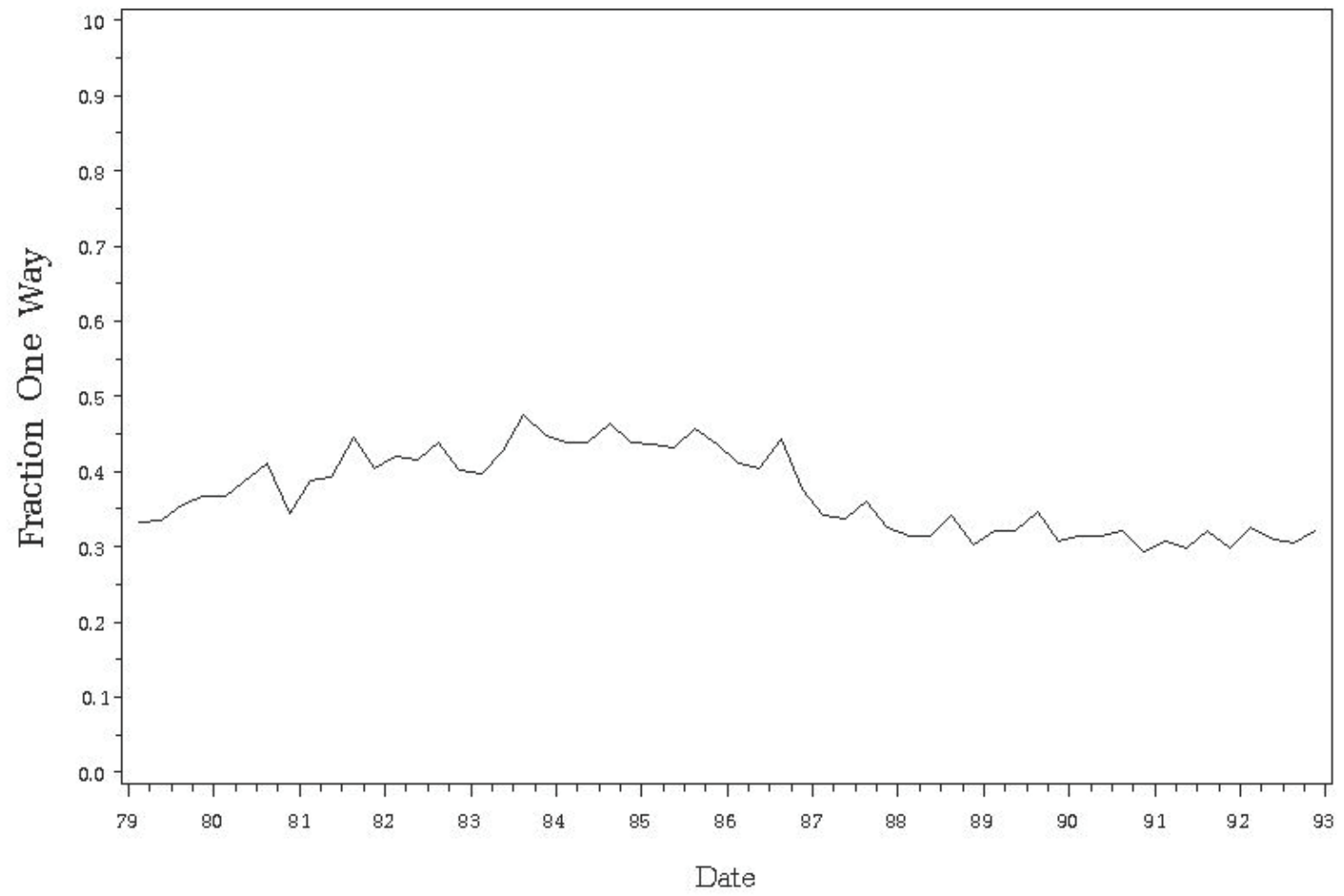

Figure 4.1 


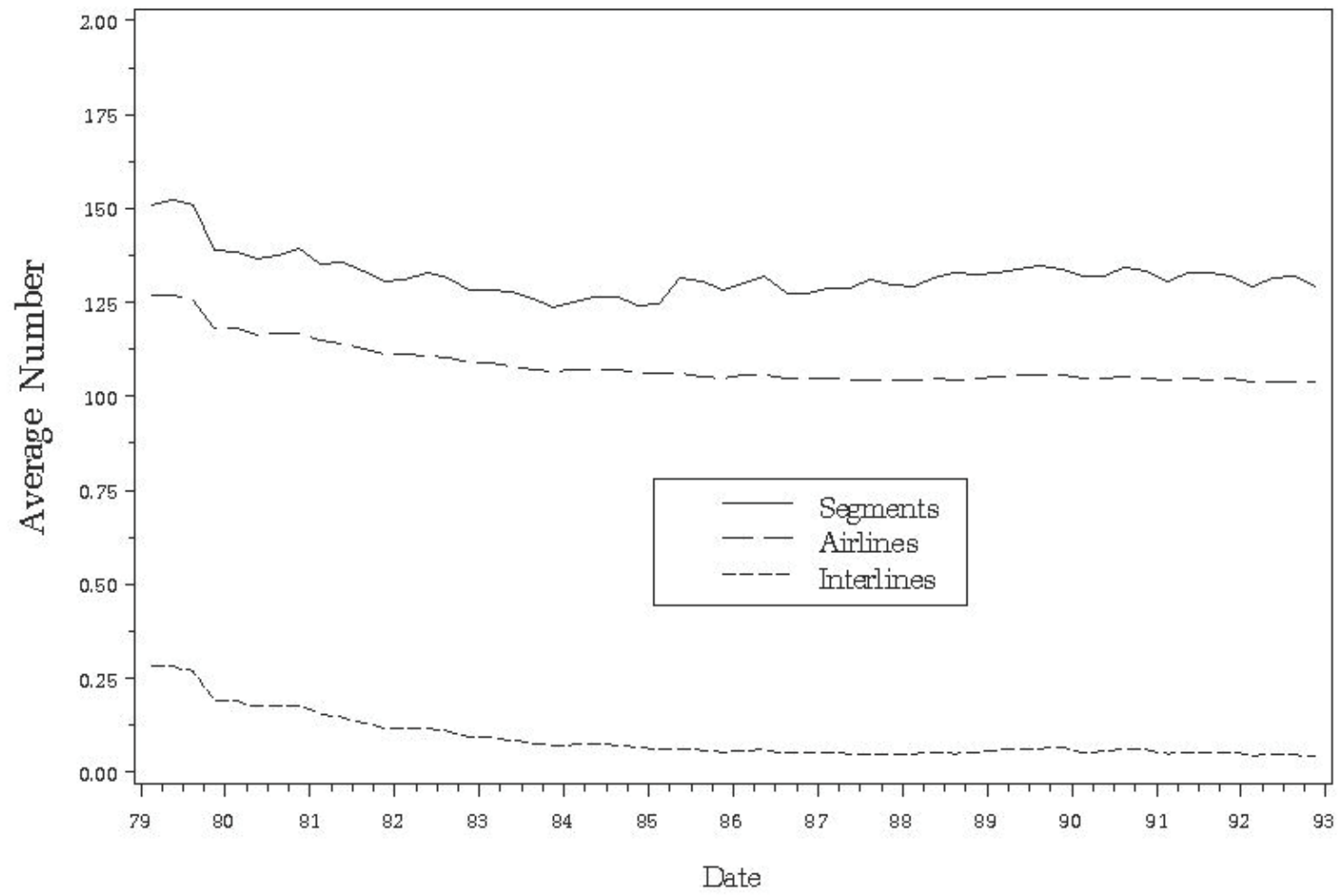

Figure 4.2 


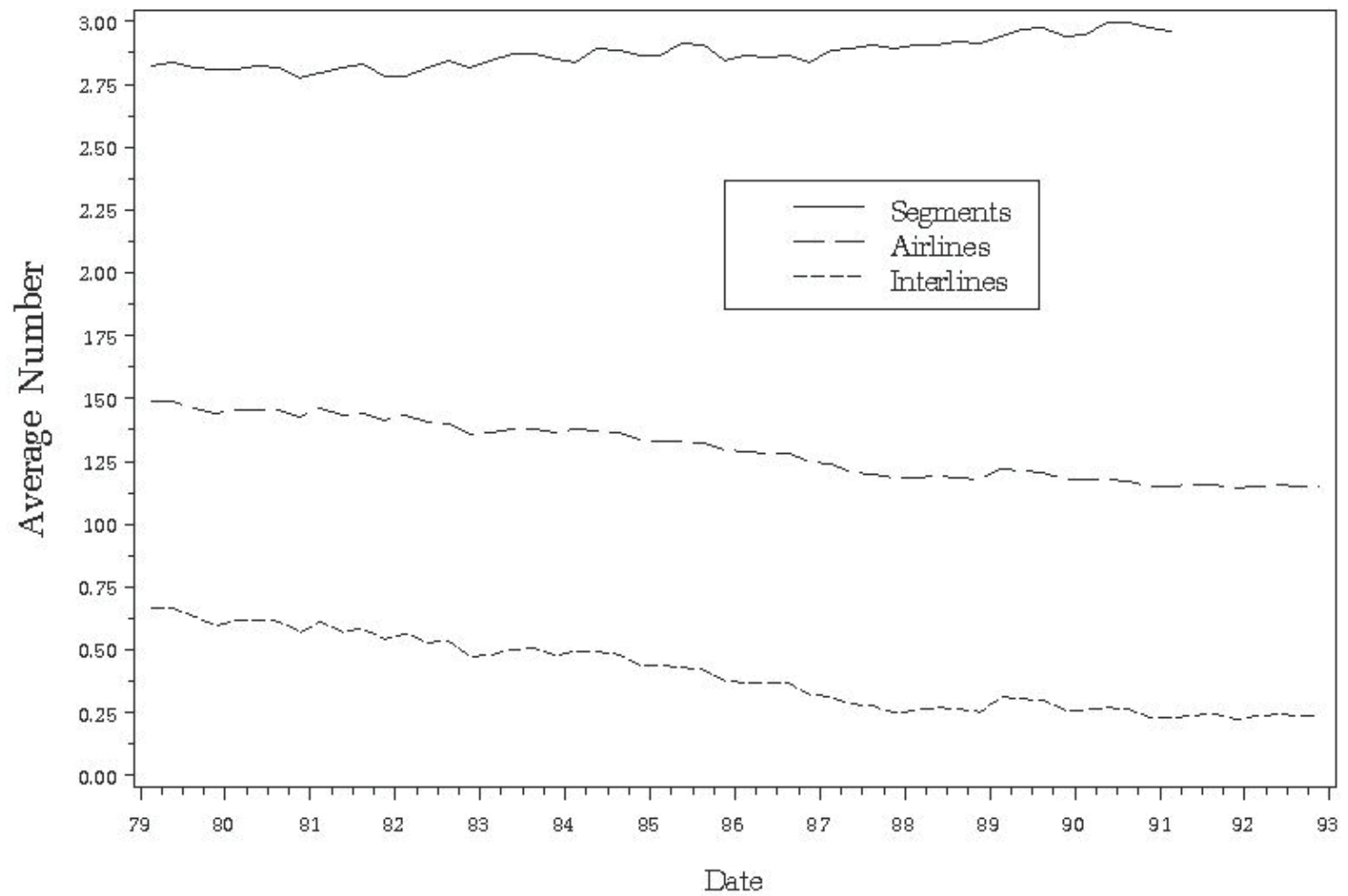

Figure 4.3 


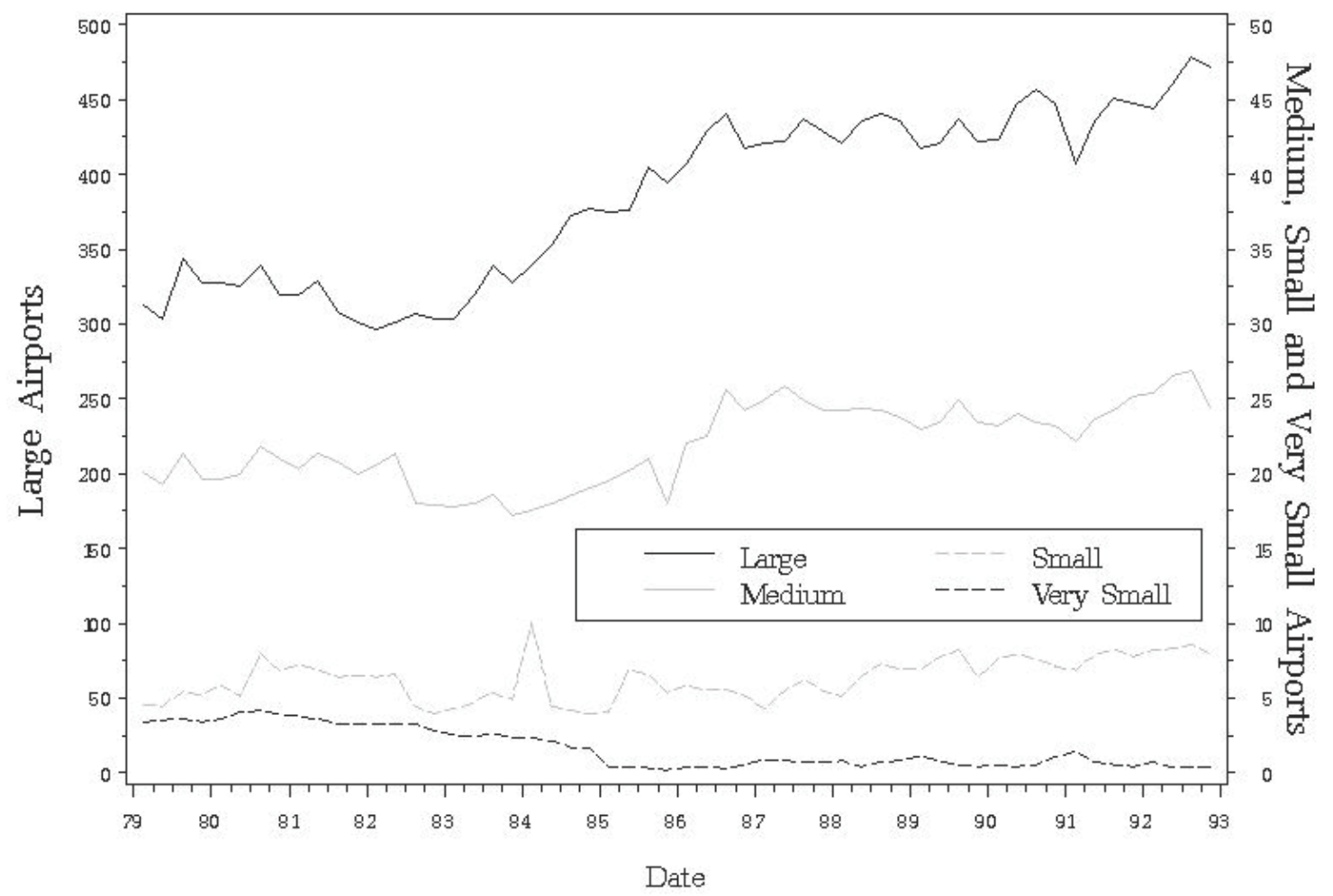

Figure 4.4 


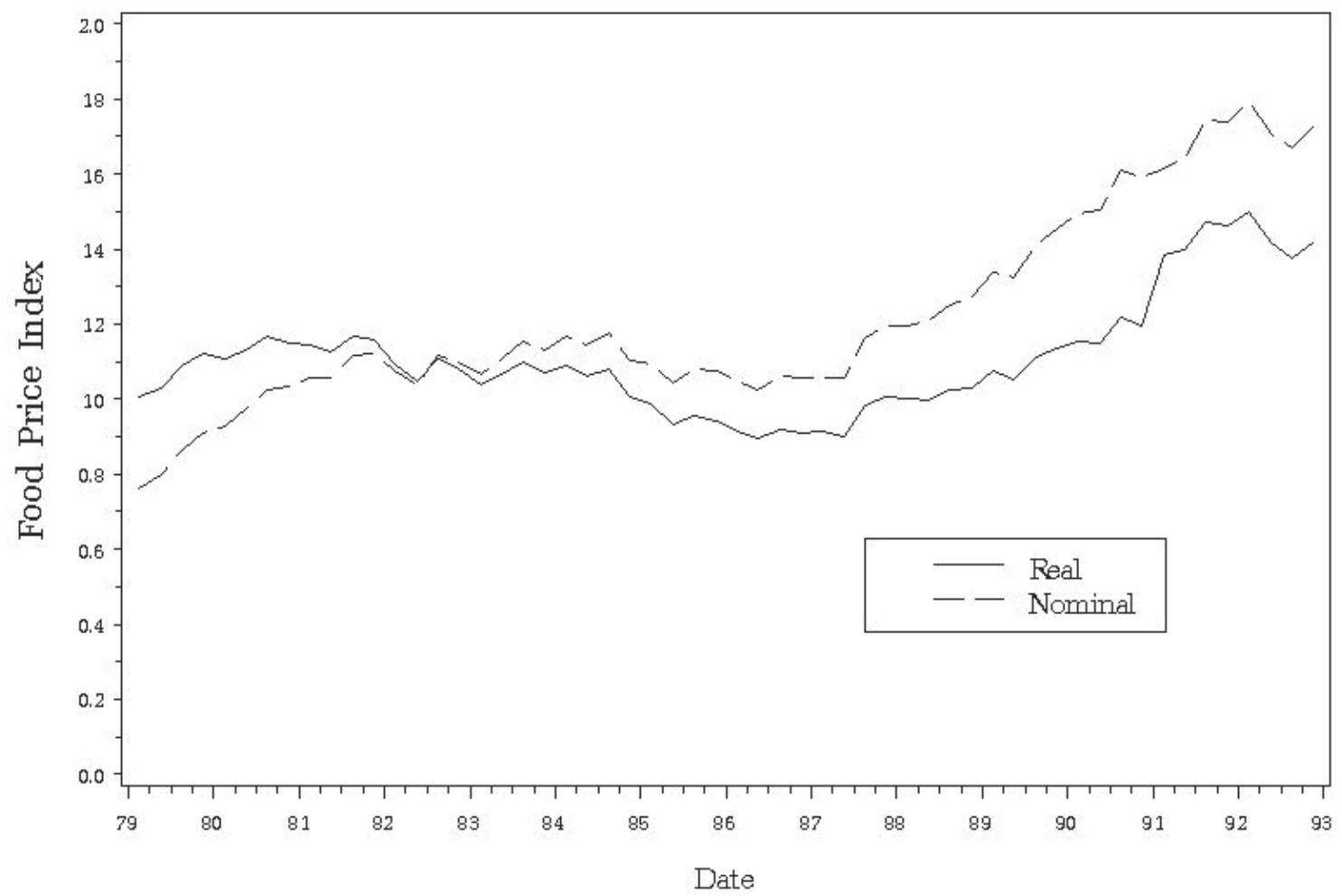

Figure 4.5 


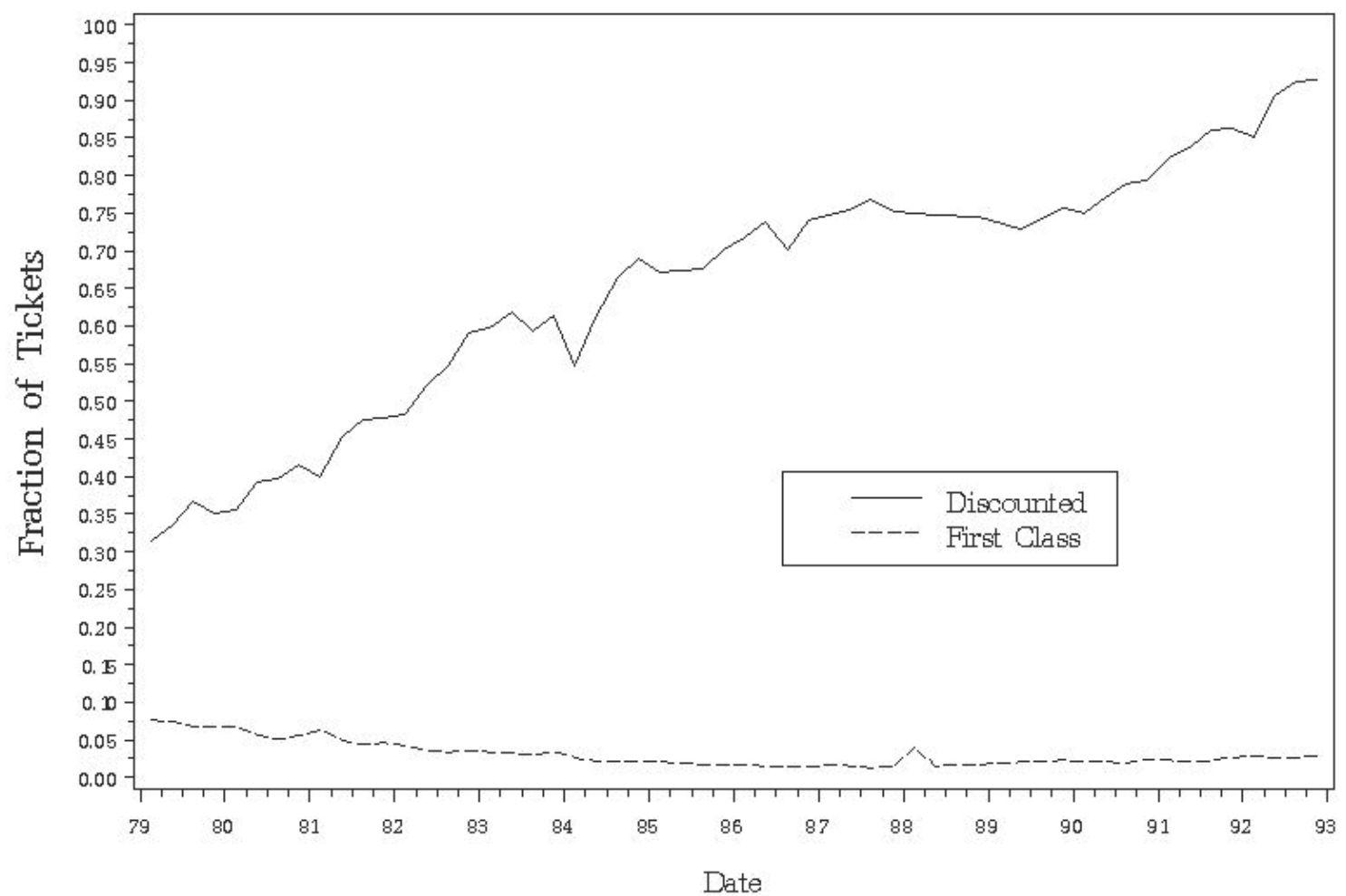

Figure 4.6 


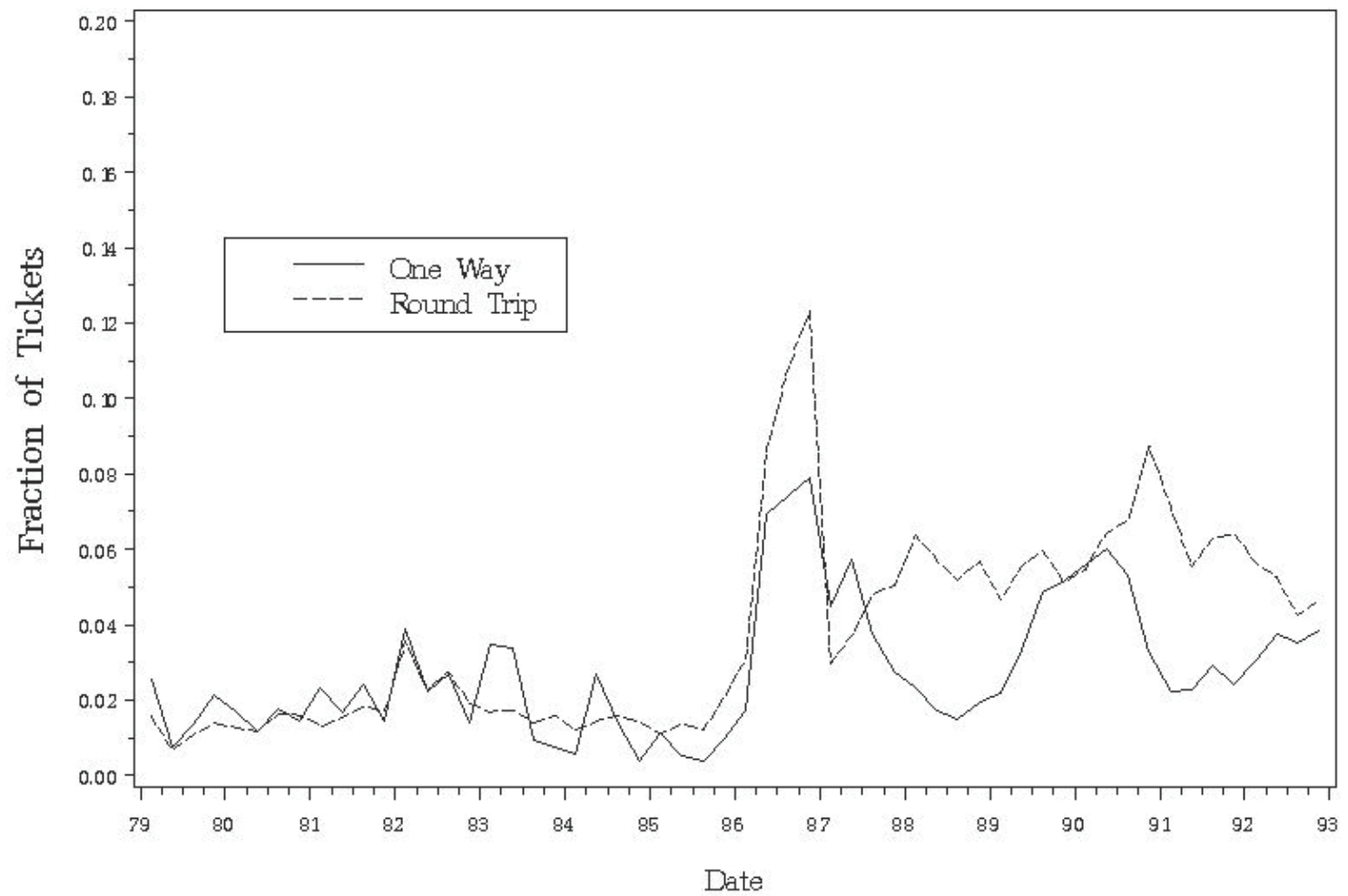

Figure 4.7 


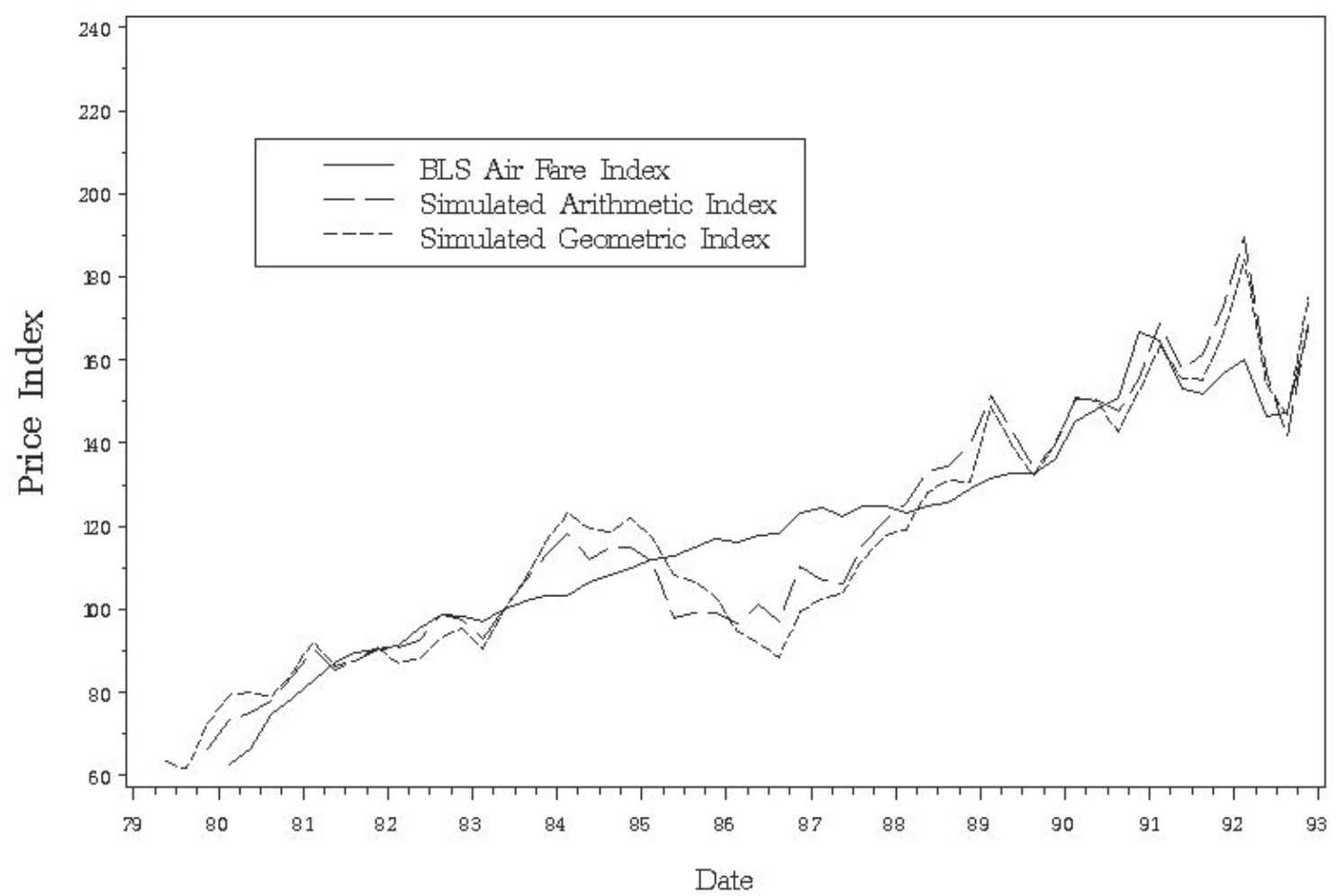

Figure 5.1 


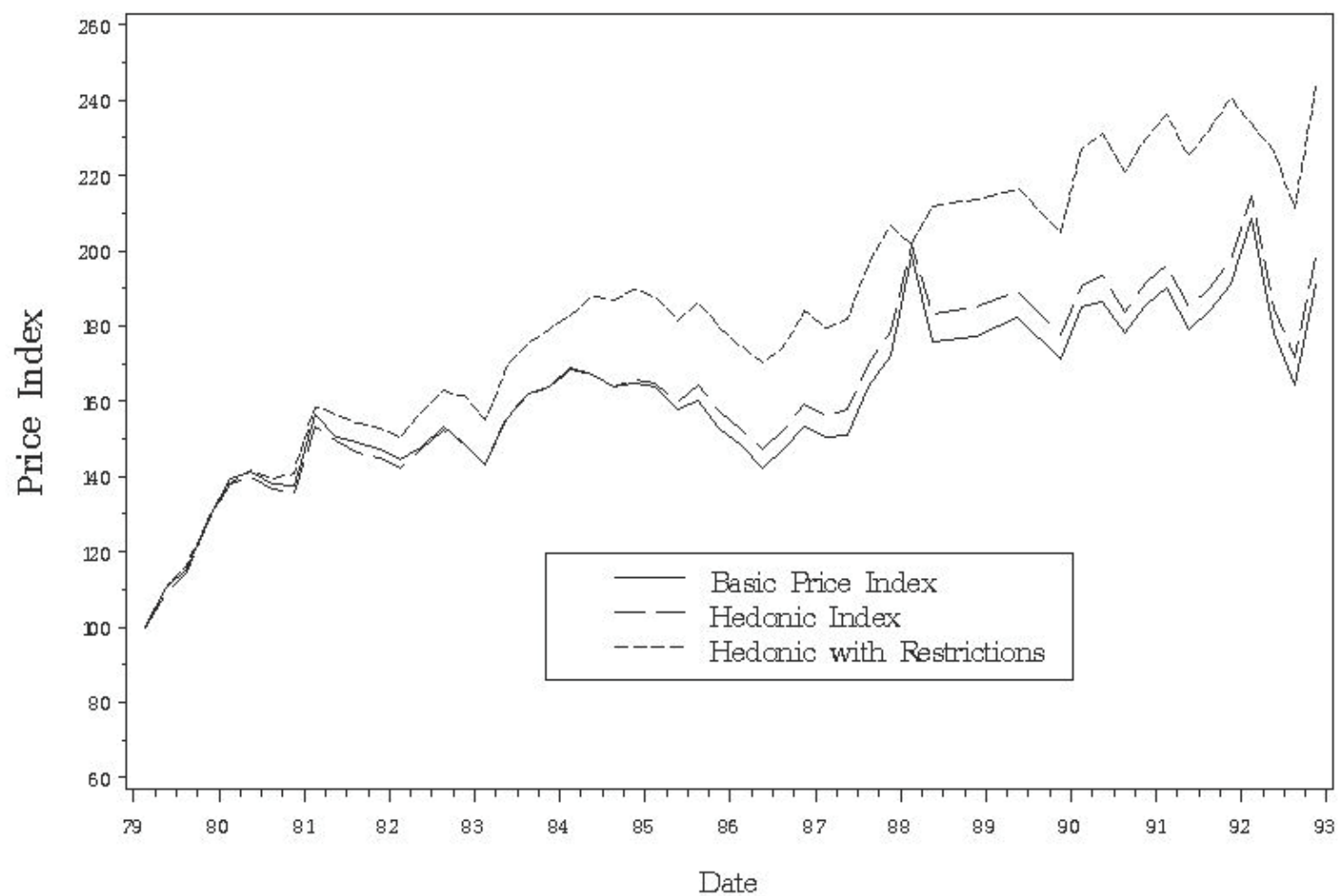

Figure 5.2 


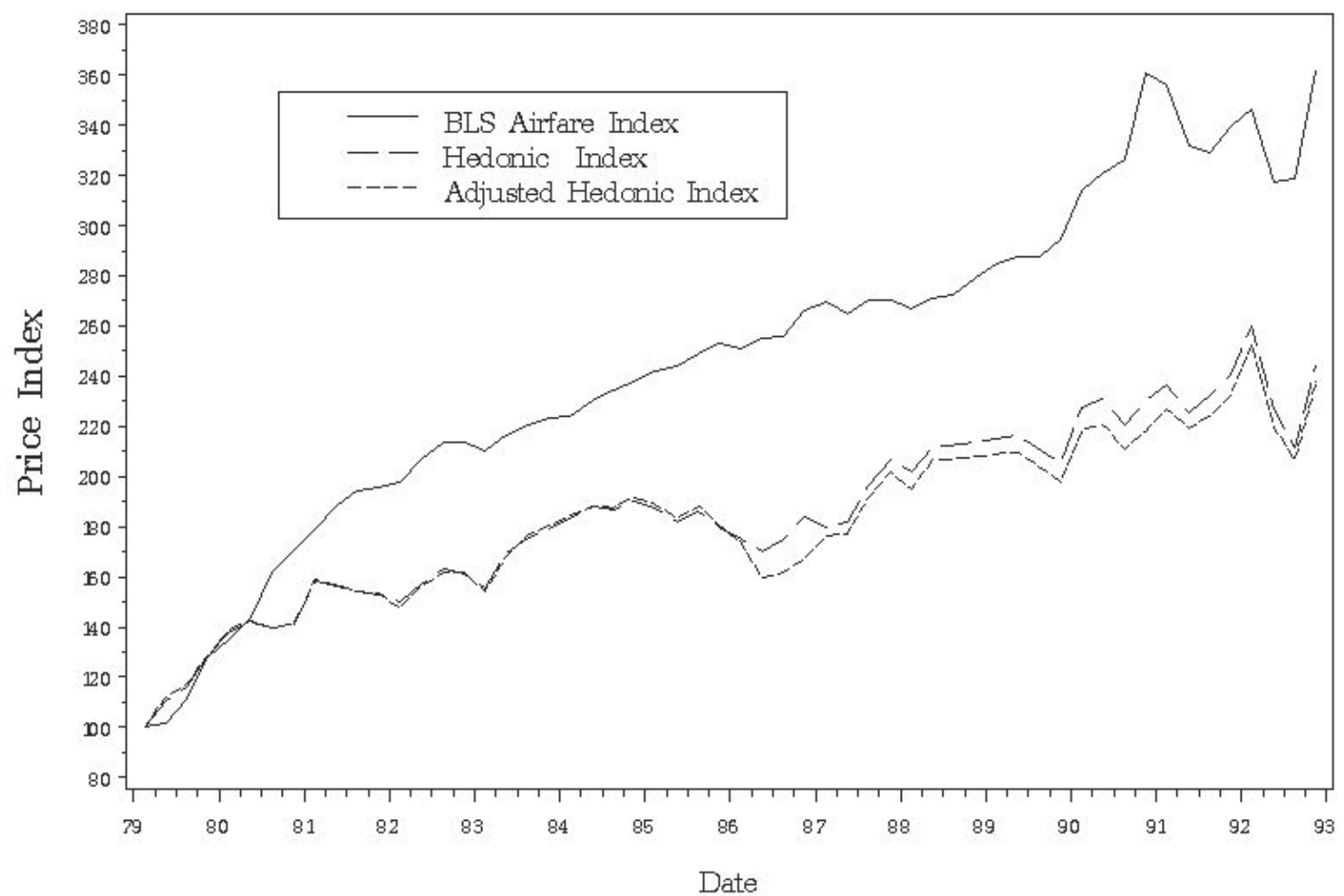

Figure 5.3 